\title{
Saharan dust electrification perceived by a triangle of atmospheric electricity stations in Southern Portugal
}

Article

Accepted Version

Creative Commons: Attribution-Noncommercial-No Derivative Works 4.0

Sliva, H. G., Lopes, F. M., Pereira, S., Nicoll, K., Barbosa, S. M., Conceicao, R., Neves, S., Harrison, R. G. and Collares Pereira, M. (2016) Saharan dust electrification perceived by a triangle of atmospheric electricity stations in Southern Portugal. Journal of Electrostatics, 84. pp. 106-120. ISSN 0304-3886 doi: https://doi.org/10.1016/j.elstat.2016.10.002 Available at https://centaur.reading.ac.uk/67778/

It is advisable to refer to the publisher's version if you intend to cite from the work. See Guidance on citing.

To link to this article DOI: http://dx.doi.org/10.1016/j.elstat.2016.10.002

Publisher: Elsevier

All outputs in CentAUR are protected by Intellectual Property Rights law, including copyright law. Copyright and IPR is retained by the creators or other copyright holders. Terms and conditions for use of this material are defined in the End User Agreement. 


\section{CentAUR}

Central Archive at the University of Reading

Reading's research outputs online 


\title{
Saharan dust electrification perceived by a triangle of atmospheric electricity stations in Southern Portugal
}

\author{
H.G. Silva, ${ }^{1 *}$ F. Lopes, ${ }^{1}$ S. Pereira,${ }^{2}$ K. Nicoll, ${ }^{3}$ S.M. Barbosa,${ }^{4}$ R. Conceição, ${ }^{1}$ S. Neves, ${ }^{1}$ R.G. \\ Harrison, ${ }^{3}$ M. Collares Pereira ${ }^{1}$ \\ ${ }^{1}$ Renewable Energies Chair, University of Évora, IIFA, Palácio do Vimioso, Largo Marquês de Marialva, \\ 7002-554, Évora, Portugal. (*hgsilva@uevora.pt) \\ ${ }^{2}$ Departamento de Física, ICT, Instituto de Ciências da Terra, Universidade de Évora, Rua Romão \\ Ramalho 59, 7002-554 Évora, Portugal. \\ ${ }^{3}$ Department of Meteorology, University of Reading, Berkshire, RG6 6BB, UK. \\ ${ }^{4}$ INESC TEC - INESC Technology and Science, Campus da FEUP, Rua Dr Roberto Frias, 4200-465 \\ Porto, Portugal.
}

\begin{abstract}
Atmospheric Electric Potential Gradient (PG) measurements were carried out in three sites forming a triangular array in Southern Portugal. The campaign was performed during the summer, characterized by Saharan dust outbreaks; $16^{\text {th }}-17^{\text {th }}$ July 2014 dust event is considered. Short time-scale oscillations of the PG at two of the stations and a mid time-scale suppression of the PG in the three stations are found. Results are interpreted as evidencing long-range dust electrification; attributed to the air-Earth electrical current creating a bipolar charge distribution inside of the dust layer. The relevance of using arrays of sensors, instead of single sited, is highlighted.
\end{abstract}

Keywords: Desert Dust Electrification, Atmospheric Electric Potential Gradient, Sensors Array, Wavelet Analysis 


\section{Introduction}

Dust storms have been receiving significant attention in the past decades (e.g., Engelstaedter et al., 2006), among different roles, because of their impact on the planetary radiative forcing and its relevance to the Earth's climate. Though little information has been collected on dust electrification (e.g. Ette, 1970; Ulanowski et al., 2007), the interest has been raised recently due to its importance in two main areas: energy systems and planetary exploration. In the former, dust electrification can have technological importance since it is of great usefulness in the development of automatic electrostatic dust particle removal for solar energy systems, as it was used on NASA's lunar missions (Calle et al., 2009). This technological improvement on Earth will permit the increase of the efficiency of solar energy systems while reducing water consumption in the cleaning activities of these systems (Sarver et al., 2013). In the latter, the understanding of Martian dust devil electrification (Delory et al., 2006) is expected to be boosted by the ExoMars mission (Esposito et al., 2014) which has deployed this year two payloads: DREAMS and MicroARES; these measuring instruments are expected to further contribute to the understanding of these phenomena on Mars. In fact, the ExoMars team is using Saharan dust storms as a way to comprehend Mars dust storms (Esposito et al., 2016). Those authors found evidence that the atmospheric electric field influences the dust-lifting process; dependent on the mineralogical composition of the dust and the atmospheric relative humidity (Esposito et al., 2016). Moreover, Williams et al. (2009) reported on the electrification of haboobs in the Sahelian belt of West Africa. Measurements were made in the (source) region where the storms developed and significant electric perturbations were found only under heavy dust loads (high concentration of large sized particles) exhibiting in most of the occurrences strong and negative unipolar electrification (absolute electric fields of $\sim 1-10 \mathrm{kV} / \mathrm{m}$ ). These observations are similar to Kamra's measurements (1972), in which the author states that most of the dust storms dominated by clay minerals tend to produce negative space charges in the source region. Nevertheless, debate still exists on ether the negative electrification comes from clay minerals (dust) or quartz minerals (sand), Williams et al. (2009).

Many open questions also exist on the way space charge generated in the source region behaves under long-range transport. In principle, only small particles (e.g., clay particles with size ranges 
from 1 to $100 \mu \mathrm{m}$ ) can be transported and according to previous observations of negative clay electrification, negative perturbations in the electric fields would have to be found away from the source region. Even so, the work of Reiter and co-authors (Reiter, 1992) seems to contradict this. The author has shown that during a Saharan dust outbreak that reached the Zugspitze Peak (Germany), a positive space charge density (SCD) at $\sim 3 \mathrm{~km}$ altitude was formed two times larger than in the normal "clean" conditions. Tropospheric LIDAR measurements showed that the dust layer was co-located with the space charge density around $\sim 3 \mathrm{~km}$ and chemical aerosol analysis showed that sand particles were dominant with significant increased concentrations of $\mathrm{SiO}_{2}$ and $\mathrm{Al}_{2} \mathrm{O}_{3}$. More recently, balloon-borne charge measurements of Saharan dust layers (up to $4 \mathrm{~km}$ ) have been made in the Cape Verde Islands, where Saharan dust outbreaks are frequently transported to. The experiment depicted a maximum absolute charge density of $\sim 25 \mathrm{pC} \mathrm{m}^{-3}$ (Nicoll et al., 2011). From background conductivity considerations any dust charge generated during lofting in the source region should have decayed long before reaching Cape Verde (Nicoll et al., 2011) and consequently no long-range electrification would be observable. For that reason, the authors argued that a possible mechanism to explain long-range dust charging was due to the vertical air-Earth electric current, imposed by the Global Electrical Circuit ${ }^{1}$ (GEC), flowing through the atmospheric electric conductivity gradient inside the dust layer (Nicoll and Harrison, 2010). The atmospheric electric conductivity gradient is a consequence of small ion scavenging by dust particles, in which the ion-particle attachment process charges dust particles (with low electrical mobilities) that significantly decrease electric conductivity (Ulanowski et al., 2007) and generates the conductivity gradient. In principle, the action of the air-Earth current would then create a positive space charge at the top of the dust layer and a negative space charge would be generated by mirror charges, forming a bipolar charge distribution. The overall charge of the dust layer would be a result from the net charge of this bipolar distribution.

Previous work on the long-range dust electrification has been focused on a single measuring site where the Atmospheric Electric Potential Gradient, usually refereed on the literature as Potential Gradient $\left(\mathrm{PG}^{2}\right)$, was recorded (e.g., Rudge, 1913). Nevertheless, recent efforts in atmospheric electricity concern the development of arrays of PG field-mills in large time ( $\sim 1$ hour) and space 1 GEC is a consequence of the Ionospheric Potential, $V_{I}$, (Rycroft et al., 2000), as it is charged in the thunderstorm active regions of the globe and discharged in the fair-weather regions by the flow of an air-Earth electric current (Conceição and Silva, 2015). The daily variation of thunderstorm activity modulates globally the PG in what it is called the Carnegie Curve (Harrison, 2013). 
scales $(\sim 100 \mathrm{~km})$, as it is the case of the network installed in South America (Tazca et al., 2014) and the one under development in Europe (COST Action 15211: Atmospheric Electricity Network). The existence of such networks raises the possibility of coordinated PG measurements to track atmospheric phenomena such as smoke plume transport, known to affect PG measurements (Conceição et al., 2015). In this context, an experiment was conceived and undertaken during the Alqueva hydro-meteorological Experiment (ALEX2014): alex2014.cge.uevora.pt. The experiment consisted on the installation of three similar PG fieldmills, in Southern Portugal, forming a triangular array that allowed the recording of PG time series during a three-month period, from June to August 2014. This period corresponds to the summer season in the northern hemisphere and represents a unique opportunity to perform such an experiment due to two main reasons: the frequency of occurrences of fair-weather days and the occurrences of isolated Saharan dust outbreaks transported over Africa to the measuring region (e.g. Preißler et al., 2011; Obregón et al., 2015). The use of arrays of sensors instead of single sensors allows regional perturbations to be distinguished from local ones and, contrary to previous thoughts on this matter, present efforts seem to encourage their use. The present work contributes to that view, adding to it the separation of short time-scale phenomena (below 1-day), more prone to local influences, e.g. cloud passage, and mid time-scale phenomena (above 1-day), more sensible to regional process, e.g. pollution.

This work is organized as follows: section 2 describes the experimental setup, section 3 outlines the Saharan dust event of July $16^{\text {th }}-17^{\text {th }} 2014$; section 4 presents the PG measurements during the ALEX2014 campaign; section 5 discusses the results and a formulation is derived to reinforce the observations; and in section 6 main conclusions along with recommendations for future work are given.

\footnotetext{
2In atmospheric electricity it is common to use PG, as means to quantify the Atmospheric Electric Field. The convention is that the $P G$ is defined by $P G=d V / d z$, where $V$ is the electric potential with respect to Earth's surface (where $\mathrm{V}=0$ ) and $\mathrm{z}$ is the vertical coordinate. By this convention the $\mathrm{PG}$ is positive for fair-weather days (according to the international standards fair-weather days are selected as those with cloudiness less than 0.2 , wind speed less than $5 \mathrm{~ms}^{-1}$ and with the absence either of fog or precipitation, Chalmers, 1967) and related to the vertical component of the atmospheric electric field $E_{z}$ by $E_{z}=-P G$.
} 


\section{Measurement campaign}

An equilateral triangle is formed by three JCI field-mills (Chubb, 2014; Chubb, 2015), separated by nearly $50 \mathrm{~km}$ from each other, forming a triangular array of about $\sim 1000 \mathrm{~km}^{2}$ in Southern Portugal (upper-panel of Figure 1). The geographic location of the three sites in which measurements of PG were conducted are: Évora (EVO) at $38.50 \mathrm{~N}, 7.91 \mathrm{~W}$; Amieira (AMI) at 38.27 N, 7.53 W and Beja Airbase (BEA) at 38.07 N, 7.93 W. The EVO and BEA sites follow almost a North-South alignment, whilst AMI is more deviated to the East and is settled approximately in the mid-way of the other two sites. The EVO station is situated in the center of the city of Évora ( $\sim 50000$ inhabitants), where major sources of pollutants are due to anthropogenic activity such as traffic, heating (winter) and cooling (summer) air systems. In EVO, a JCI 131 was installed in the University of Évora campus (at $2 \mathrm{~m}$ height) with few trees and two University buildings in its surroundings ( $\sim 50 \mathrm{~m}$ away). The instrument was calibrated in 2012 and has been operating since 2005. The AMI station is located on the shoreline of the Southern part of the Alqueva reservoir (currently one of the largest man-made lake in western Europe), set upon a hill approximately $30 \mathrm{~m}$ above the lake water level, with low vegetation in its surroundings (Lopes et al., 2015). The BEA station is located further south on an air base in the outskirts of the small city of Beja ( $\sim 0000$ inhabitants). In AMI and BEA two identical fieldmills JCI 131F were used and installed as well at $2 \mathrm{~m}$ height above the ground. Measurements in the three sites were made every second and 1-minute average values recorded. A quality control criterion for the raw data was used, and values within the precision threshold of the field-mills $(\sim|1| \mathrm{V} / \mathrm{m})$ were rejected. This allows the removal of values that correspond to equipment malfunction and/or maintenance, such as when a field-mill stops operating but the data logger continues to record.

The characterization of the aerosol conditions in the region was based on the AERONET (AErosol RObotic NETwork) station located at EVO. An automatic sun tracking photometer (CIMEL CE-318-2) is operated to measure aerosol optical depths (AOD) at several wavelengths in the range of $340-1640 \mathrm{~nm}$. AOD is a measure of the solar radiation extinction due to the aerosol load present in the atmospheric column; more details can be found in (Holben et al., 1998). The spectral dependence of the optical depth defines the Angstrom Exponent (AE) based on the ideas developed by Angstrom (1924). AE provides information on the size distribution of the aerosol population (i.e., aerosol fine and coarse modes relative proportion). When coarse 
particles are in large proportion in the aerosol population, $\mathrm{AE}$ tends to be low, i.e., lower than 1. $\mathrm{AOD}$ and $\mathrm{AE}$ data can be retrieved from the AERONET webpage: aeronet.gsfc.nasa.gov

Finally, solar radiation curves (technical definition being global horizontal irradiance, GHI) were measured in EVO station with a 10 minutes rate using an Eppley pyranometer (model 8-48).

\section{Desert Dust Transported into Southern Portugal}

Figures 1a-1d present a set of Hysplit backward trajectories for the $15^{\text {th }}, 16^{\text {th }}, 17^{\text {th }}$ and $18^{\text {th }} \mathrm{July}$ 2014, respectively. HYbrid Single Particle Lagrangian Integrated Trajectory model (Hysplit) can be found here: ready.arl.noaa.gov; details of the theory behind the model can be found in (Stein et al., 2015). Red trajectories correspond to particles arriving at altitudes of $2 \mathrm{~km}$, blue ones to $2.5 \mathrm{~km}$ and green ones to $3 \mathrm{~km}$. These altitudes are selected according to the typical altitudes at which Sahara desert dust arrives at Southern Portugal (Obregón et al., 2015). Four day backward trajectories ending at 12 UTC were considered for the three days. The most important feature in these figures is the transition from Eastward trajectories on the $15^{\text {th }}$ July, bringing clean air from the Atlantic Ocean, to Southward trajectories on the $16^{\text {th }}-17^{\text {th }}$ July, bringing dust from the western part of Sahara Desert. The $16^{\text {th }}-17^{\text {th }}$ July backward trajectories are persistently over Moroccan territory, in the western part of the Sahara Desert, which triggered the transport of dust towards the Iberian Peninsula. On the $18^{\text {th }}$ July a reverse transition occurs and the Southward trajectories become Eastward trajectories as they were on the $15^{\text {th }}$ July.

Figure 2a shows the aerosol optical depth and Angstrom Exponent measured at Évora station. The measurements show a clear signature of dust on $16^{\text {th }}-17^{\text {th }}$ July, with a visible increase in the atmospheric turbidity (AOD increases from normal background levels of $\sim 0.1$ to $\sim 0.3$ ), and low wavelength dependence (AE decreases from typical values of $\sim 2$ to $\sim 0.2$ ), e.g. Preißler et al., (2011). The combination of sun-photometer measurements and backward trajectories makes it clear that dust is present over the region under analysis. Satellite information was also retrieved from the CALIPSO satellite borne lidar, CALIOP (Winkler et al., 2007), data available at: eosweb.larc.nasa.gov. The CALIOP total attenuated backscatter $(532 \mathrm{~nm})$ profile for the dawn of $18^{\text {th }}$ July is shown in Figure $2 \mathrm{~b}$. The respective depolarization profile (not shown here) confirms that these aerosols are of dust type. The inset shows in green the satellite path, the horizontal 
black line is above the latitude where the PG sensors were located and the red one points roughly the region where the satellite path crosses the western part of the Sahara desert (the satellite path passes nearly $200 \mathrm{~km}$ westward of the array location). The backscatter profiles of the intersection points between the black and red lines with the satellite path are marked by black and red vertical lines, respectively, in the main picture. The figure shows the profile of the dust (evidenced by a greenish colour on the depolarization ratio plots) along the satellite path on the western part of the Sahara desert at latitudes that go from $\sim 28^{\circ}$ to $\sim 18^{\circ}$. This confirms the discussion on the backward trajectories in which the dust is brought aloft at the western part of the Sahara. It is worth mentioning that the heights of the dust shown by CALIPSO are consistent with the heights shown in the trajectory plots.

Maps and dust profiles from the BSC-DREAM8b model (Dust REgional Atmospheric Model) based on the Barcelona Supercomputing Center are shown in Figure 3. Detailed description of the model can be found in the literature (Pérez et al., 2006a; Pérez et al., 2006b and Basart et al., 2012), whereas the data is freely available on the project webpage:

bsc.es/projects/earthscience/BSC-DREAM/. The successive maps for $15^{\text {th }}-18^{\text {th }}$ July are shown in Figures 3a-3d, respectively, demosntrating that dust loads of $\sim 0.5 \mathrm{~g} / \mathrm{m}^{2}$ start to develop in the western part of the Saharan desert on the $15^{\text {th }}$ July. The dust loads in that part of the desert increased on the following two days: $16^{\text {th }}-17^{\text {th }}$ July; then started to spread northeastwards towards Portugal. According to the model the dust outbreak reaches the location of the PG sensors on the $16^{\text {th }}$ July, around 12 UTC, in agreement with the AERONET measurements shown in Figure 2a. On the $17^{\text {th }}$ July the dust covers practically all Iberia with dust loads lower than $\sim 0.25 \mathrm{~g} / \mathrm{m}^{2}$. The following day, $18^{\text {th }}$ July, shows that the dust load in the western part of Sahara desert continues to increase in certain regions $\left(\sim 1.5 \mathrm{~g} / \mathrm{m}^{2}\right)$, although the dust is no longer over Portugal in the region of the PG sensors. The model dust profiles shown in Figure 3e confirms this point of view, with the height of the dust layer typically extending from the surface up to $3 \mathrm{~km}$. On the $15^{\text {th }}$ and $18^{\text {th }}$ July there is effectively no dust and on the $16^{\text {th }}$ July a dust layer develops from $0.5 \mathrm{~km}$ in altitude up to $2.5 \mathrm{~km}$, whereas on the $17^{\text {th }}$ July the dust layer profile goes from $1 \mathrm{~km}$ to $3 \mathrm{~km}$. On both days the maximum dust load is estimated to be $\sim 50 \mu \mathrm{g} / \mathrm{m}^{3}$ - therefore a relatively weak desert dust outbreak. An interesting remark is the fact that the maximum diffuse solar radiance (technically diffuse horizontal irradiance, DHI) for EVO on the dust event days $\left(16^{\text {th }}-17^{\text {th }} \mathrm{July}\right)$ 
was $\sim 200 \mathrm{~W} / \mathrm{m}^{2}$, twice the value for $15^{\text {th }} \mathrm{July}$, probably additional confirmation of the presence of the desert dust plume.

Finally, an animated Graphics Interchange Format (GIF) representation of the SEVIRI Image Data from METEOSAT for the $15^{\text {th }}$ to $18^{\text {th }}$ of July is available on supplementary material, Figure S1. The representation is made with RGB channels and the indication of time is on UTC. The animatiion seems to confirm the presence of the dust plume on the western part of Morocco being transported to the South of Portugal on the $16^{\text {th }}$ and $17^{\text {th }}$ of July 2014.

\section{Potential Gradient}

This section intends to evidence PG perturbations, on $16^{\text {th }}-17^{\text {th }}$ July, as a result of the presence of the Saharan dust over Southern Portugal. If such perturbations are proved to be unique to the desert dust event, these might be interpreted as evidences of the long-range desert dust electrification and a model can be discussed (in the next section) to explain the observations. Three analyses are made to that end: (i) A daily analysis of the PG data for the three stations; (ii) A robust lowess (locally weighted linear regression) smoothing of the PG data for the three stations; (iii) A wavelet analysis over the 1-hour averaged PG data for the three stations.

\subsection{Daily analysis}

To examine possible short time-scale (below 1 day) effects of the Saharan dust on the PG measurements (as retrieved by the triangle of sensors), the daily variation in PG for each of the three sites is represented in Figures 4, 5 and 6, respectively for BEA, AMI and EVO. Dark blue rectangles mark the days of the dust event, $16^{\text {th }}-17^{\text {th }}$ of July, and the first and second dark red rectangles mark the day before, $15^{\text {th }}$ July, and after the event, $18^{\text {th }} \mathrm{July}$, respectively. The thick black lines in the plots represent the lowess smoothed mean daily variation (i.e., the mean daily cycle with a lowess curve superimposed) of the FW PG for the entire ALEX2014 campaign in the respective stations (used as comparison). FW days were determined based on the daily GHI curves in EVO (Figure S2 in supplementary material). A reference GHI curve was obtained by lowess smoothing the mean daily variation of six undisturbed GHI curves ( $7^{\text {th }}$ to $12^{\text {th }} \mathrm{July}$ ); correlation of the reference curve with the GHI curves for each day permitted the selection of 
Disturbed-Weather (DW) days, having correlations below 0.99, and Fair-Weather (FW) days, with correlations equal or above 0.99 . This criterion could be calibrated with cloud cover data and a given cloud cover attributed to a given correlation, nevertheless, such procedure is out of the scope of the present manuscript. The indication of DW and FW appears in the lower-right corner of the PG panels in Figures 4, 5 and 6. It should be said that $16^{\text {th }}-17^{\text {th }}$ of July (the days of the dust event) appear to be FW days, what should rule out clouds or other disturbed meteorological phenomena as the cause for the possible PG perturbations on those days.

Moreover, BEA station data, Figure 4, shows that PG on the $15^{\text {th }}$ July tends to follow the mean daily behaviour, as expected for a FW day, and a similar tendency occurs on the $16^{\text {th }} \mathrm{July}$, despite the beginning of the dust event. On the $17^{\text {th }} \mathrm{July}$, the day in which the dust event is fully developed (as confirmed by the AE in Figure 2a) evident perturbations on the PG take place between 8 and 10 UTC, in which the PG oscillates approximately around $\pm 200 \mathrm{~V} / \mathrm{m}$. Such sharp inversions are rare on FW days, as it is the case, and are usually attributed to cloud passage on DW conditions. In fact, similar oscillations are found in BEA, but for DW days, e.g., on the $23^{\text {rd }}$ June and $29^{\text {th }}$ July. The only FW day in which the PG perturbations resemble those of the dust event, $17^{\text {th }}$ July, occur on the $28^{\text {th }}$ July, in which the PG inversion goes down to approximately $-120 \mathrm{~V} / \mathrm{m}$, but no oscillations are found. The unusual behaviour of the PG supports the hypothesis that the PG oscillations observed on the $17^{\text {th }}$ July can be attributed to the long-range dust transport.. In line with this, the day following the dust event reveals that the PG, once again, follows the mean daily behaviour.

Contrary to this observation, the AMI station does not show any considerable change in the PG behaviour during the dust event, $16^{\text {th }}-17^{\text {th }}$ July (dark blue rectangles), presented in Figure 5. This is surprising as it was demonstrated in Figure 3 that the dust during these dates covered the entire region of Southern Portugal; the region in which the three stations are located. There are several possible explanations for this, which include both horizontal and vertical variations in the dust concentration as well as variations in the charge distribution within the layer, which could lead to more noticeable effects on the PG at some sites than others. Another explanation includes a possible screening effect from charges generated by the Alqueva lake in the proximity of this 
station. Charging mechanisms affecting this station are discussed by the authors elsewhere (Lopes et al., 2016) and could constitute a mechanism to suppress the short time-scale influence of the desert dust electrification. Interestingly, at mid time-scales the influence of the desert dust is perceived as will be shown below.

Finally, EVO station again evidences PG perturbations during the dust event, shown in Figure 6. On the day before the Saharan dust event, $15^{\text {th }}$ July, the PG follows closely the mean daily behaviour as anticipated (considering no dust has arrived at the station yet). During the following days significant variations in the PG are observed at the end of $16^{\text {th }}$ July ( 22 UTC) and during all of the $17^{\text {th }}$ July, with PG values reaching around $-390 \mathrm{~V} / \mathrm{m}$, which is uncharacteristic of a normal FW day. On the day after the dust event, $18^{\text {th }}$ July, the PG curve resumes its normal mean behaviour again. To examine the likelihood of such negative PG excursions occurring during other FW days without dust, Figure 6 demonstrates that such behaviour does occur at EVO (e.g $27^{\text {th }}$ June). In fact, on 22 out of $46 \mathrm{FW}$ days $(\sim 50 \%)$ the PG is shown to go negative (potentially a result of variations in local aerosol concentration), although the magnitude of the excursions are typically smaller and less frequent than the ones on the $17^{\text {th }}$ July shown in Figure 6.

To quantify the PG perturbations found at BEA and EVO on the $17^{\text {th }}$ July in a statistical sense, two parameters have been estimated for the FW days of the ALEX2014 campaign: (i) Number of local minima - local minima of the smoothed PG daily curves (indicating PG negative inversions) - represented as blue points and referred to the left y-axis of Figure 7; (ii) Relative Std (\%) - percentage of the daily standard deviation divided by the daily mean PG - represented as red points and referred to the right $y$-axis of Figure 7. The vertical black dashed line on Figure 7 marks the start of the dust event, $16^{\text {th }} \mathrm{July}$, and the day of most interest, $17^{\text {th }} \mathrm{July}$, is right after it. The analysis is also made for AMI (for consistency) though nothing worth mentioning is expected for this station for the reasons explained above. Two main features, related with the Saharan dust event, are observed: (i) the number of local minima is 15 during the day of the dust event on $17^{\text {th }}$ July, for both BEA and EVO, which is larger than the $\sim 11$ minima observed the previous day; only one FW day in BEA and three other FW days in EVO have the same number of minima. (ii) An increase in the Relative Std from the day the dust event started, $16^{\text {th }} \mathrm{July}$, to 
the following day when it was fully in progress on $17^{\text {th }}$ July, is observed. At the BEA station the Relative Std increased from $30.6 \%$ to $63.7 \%$ (more than doubled) and in the EVO case from $38.4 \%$ to $92.4 \%$ (almost tripled); this reveals an increase of the PG variability during the dust event, in fact, only four FW days in BEA exceed the Relative Std of $17^{\text {th }}$ July and only three in EVO.

Returning to the timing of the arrival of the dust, the BSC-DREAM8b maps (Figures 3a-3d) depict that the desert dust event, $16^{\text {th }}-17^{\text {th }}$ July, arrived at the two stations approximately at the same time, at least in the time scale of the dust plume transport (from hours to days), which means that the influence of the desert dust is a good candidate to explain these observations at a regional scale. The regional nature of this observation is a first highlight of the importance of using arrays of sensors instead of single sensors.

In this spirit, the BSC-DREAM8b maps (Figures 3a-3d) depict that the desert dust event, $16^{\text {th }}$ $17^{\text {th }}$ July, arrived at the two stations approximately at the same time, at least in the time scale of the dust plume transport (from hours to days), which means that the influence of the desert dust is a good candidate to explain these observations at a regional scale. The regional nature of this observation is a first highlight of the importance of using arrays of sensors instead of single sensors.

\subsection{Robust lowess smoothing}

To proceed with the analysis, the effect of the desert dust electrification at mid time-scales (above 1-day) are now explored. To that end lowess smoothed PG curves (black thick lines) are represented along with the PG raw data for BEA, AMI and EVO, respectively, in Figures 8a, 9a, and 10a, during the ALEX2014 campaign. A similar modulation of the lowess curves around the time of the dust event at the three stations sustain the occurrence of a regional process. The PG is also observed to reduce on the days following the dust event. Local minimum of the lowess curves are found at the mid-day of $19^{\text {th }}$ July at BEA and AMI, $71.8 \mathrm{~V} / \mathrm{m}$ and $49.1 \mathrm{~V} / \mathrm{m}$, respectively; while in EVO the minimum occurs $\sim 12$ hours later reaching $\sim 50.1 \mathrm{~V} / \mathrm{m}$. If the mean 
PG value for the entire ALEX2014 campaign is used as reference, for each of the three stations, this represents a reduction of the PG of around $88.7 \%, 82.6 \%, 67.3 \%$, respectively for BEA, AMI and EVO. The percentage of reduction in the three stations is fairly similar and qualitatively confirms the influence of a regional process. A possible explanation for this reduction, two days after the on set of the Saharan desert dust on the region, is the dispersion of the negative charges that were accumulated on the bottom of the dust layer; occurring after the dust layer passed. Such charge suspended in the atmosphere would increase the atmospheric electric conductivity and through (quasi-static) Ohm's law it would imply a reduction of the PG. This possibility will be discussed below.

\subsection{Wavelet analysis}

Wavelet analysis is used to understand the evolution in time of the characteristic frequencies/periods composing the time-series. The interested reader is referred to the explanatory work of Torrence and Compo (1998); the basic technique behind wavelets is the Fourier transform, transforming the signal from the time domain to frequency (or period) domain, but instead of performing one transform for the entire the time-series, successive transforms are made by the use of a wavelet function, the so called mother function, to depict the evolution of those frequencies (or periods).

In fact, $\mathrm{PG}$ is affected by different periodicities, (e.g. Silva et al. 2014), but the one of most importantance is the 1-day periodicity, which is a result of the GEC. Thus monitoring the evolution of that periodicity can reveal the influence of local/regional processes on the PG, e.g. local pollution, which disguises the behaviour imposed by the GEC. For this reason attention is given here to the 1 day periodicity. Wavelet analysis of the PG measurements at BEA is represented in Figure $8 \mathrm{~b}$ and is generally similar to those observed in AMI and EVO, shown in Figures $9 \mathrm{~b}$ and 10b, respectively. The colour gradient in the plots represents the isopower lines for a given frequency/period, lower powers appear in blue and higher powers in red. The most significant information extractable from the wavelet periodogram for BEA and EVO is the persistence of the 1-day periodicity that appears to be diminished, in a more significant way at EVO, during the desert dust event; while for AMI no change is observed. Interestingly, a 
suppression of lower periodicities, below the 1/2-day periodicity, is observed after the dust event, around the $19^{\text {th }}$ July. It reveals a lower influence of short time-scales phenomena, usually of local nature, and is another indication of the prevalence of a regional process (at mid time-scales) as revealed by the lowess analysis. With this view, the periodicity analysis is consistent with the observations described in previous sections. Revealing, in the frequency/period domain, that the desert dust affected more considerably the EVO station and also BEA (although slightly less significantly), while almost no effect is found at AMI.

\section{Dust charge model}

To understand the influence of the Saharan dust electrification on the PG measurements a model is discussed in this section.

Before considering the mathematical details of the model, it is worth discussing the electrification mechanism considered in the present model. Dust electrification is usually recognized to result from contact and triboelectric charging between particles being lofted from the surface. The basic mechanism for charge separation is commonly thought to be the fact that, during collisions, the smallest grains gain negative charge with respect to larger particles (Freier, 1960; Inculet et al., 2006; Duff and Lacks, 2008). After this size dependent charging, the smallest particles are separated from the larger ones by gravitation inducing what might be called gravitational charge separation, which is consistent with the PG observations in the dust storms source region (e.g., Williams et al., 2009; Kamra, 1972). Nevertheless, the contact and triboelectric charging depends strongly on the grain collision frequency and though high frequencies are expected in dust storms near to the source region to cause dust electrification, this is not the case for regions far away from it, as is the present case. The layers that reach distant locations have low dust concentrations; which corresponds to low collision frequencies which mean that contact and triboelectric charging are unlikely charging mechanisms. Assuming that dust charge decays on time-scales of minutes (based on the typical electrical relaxation time of air near the surface) a dust layer will lose its charge if a charging mechanism is absent. Consequently, the dust layers will no longer be charged when far from the source region. Thus, to explain long-range electrification, in the absence of other apparent mechanisms, it is reasonable to consider that the charging of the dust layers may be due to the action of the air- 
Earth electric current. In accordance to the discussion in Nicoll et al. (2011), a layer of uncharged dust particles will scavenge atmospheric ions by attachment to the large dust particles, reducing the air conductivity in that region. Such reduction in conductivity results in the creation of a space charge density (SCD) by the action of the air-Earth current, $J_{z}$, as follows: air-Earth electric current, flowing from the Ionosphere to the Earth's surface, will bring to the upper part of the dust layer positive small ions which will attach to the dust particles. This accumulation of charge will create a positive SCD, at the top of the dust layer, while a similar but negative SCD will be formed at the bottom of the dust layer due to upward flow of negative ions in the air-Earth electric current.

Figure 11 depicts a schematic diagram of the model which will be used to interpret the Southern Portugal PG data during the dust event. Basically two phenomena have been observed: (i) Short time-scale perturbations, below 1-day, of the PG at BEA and EVO, in which variations that reached $\pm 300 \mathrm{~V} / \mathrm{m}$ were observed; (ii) Mid time-scale suppression, above 1-day, of the PG at the three stations, with reductions of $\sim 80 \%$ in relation to the mean FW values. For FW days in clean sky conditions (i.e. low aerosol concentration) the $\mathrm{PG}$, represented in Figure 11 by $F_{\mathrm{c}}$, points upwards from the ground and has the typical value for those conditions, $\sim 100 \mathrm{~V} / \mathrm{m}$. When a stable dust layer is interposed, theoretically, a bipolar charge distribution is formed by GEC action through the air-Earth current as described above., with positive space charge at the top of the dust layer and negative space charge at the base. Such negative space charge would then induce positive space charges near the ground (i.e. in the vicinity of the electric field mills) beneath. As a consequence of the distribution of charges between the bottom of the dust layer and ground, a downward pointing PG ( $F^{\prime}$ in Figure 11) is generated below the dust layer. In such a situation the PG measured under the dust layer, $F_{\mathrm{d}}$, is basically $F^{\prime}$ :

$$
F_{d}=F^{\prime}=-\left|F^{\prime}\right|
$$

In the case when $F^{\prime}$ is high (i.e. when the dust layer is sufficiently close to the ground and significant space charge accumulation occurs), $F_{\mathrm{d}}$ would evidence expressive negative excursions; this mechanism is suggested to explain the PG perturbations observed at both BEA and EVO during the Saharan dust event on $17^{\text {th }}$ July. In normal FW conditions $F_{c} \approx 85.3 \mathrm{~V} / \mathrm{m}$ for BEA and $F_{c} \approx 99.7 \mathrm{~V} / \mathrm{m}$ for EVO (based on the mean daily behaviour), however during the dust event on $17^{\text {th }}$ July, the observed negative excursions reached $F_{\mathrm{d}} \approx-119.5 \mathrm{~V} / \mathrm{m}$ for BEA and $F_{\mathrm{d}} \approx$ -388.7 for EVO demonstrating that significant space charge is likely to be present. Such space 
charge corresponds to a downward pointing PG generated by the dust layer of $\left|F^{\prime}\right| \approx 119.5 \mathrm{~V} / \mathrm{m}$ for BEA and $\left|F^{\prime}\right| \approx 388.7 \mathrm{~V} / \mathrm{m}$ for EVO. The observed oscillations are then a consequence of fast charge formation/recombination on even shorter time-scales, below 1-hour.

Returning to the model presented in Figure 11 it is expected that $F$ ' would depend on the SCD between the bottom of dust layer and the ground during the desert dust event. In fact, the steadystate $F^{\prime}$ can be estimated from Gauss' law, that relates the vertical variation of $F^{\prime}$ with $\mathrm{SCD}$, usually represented by $\rho(z)$, through the relation:

$$
\frac{d F^{\prime}}{d z}=\frac{\rho(z)}{\varepsilon_{0}},
$$

here $\varepsilon_{0}$ is the permittivity of vacuum and $z$ the vertical altitude. To integrate this equation a region from the ground to the upper-limit of the SCD in the bottom of the dust layer needs to be defined; it is represented by a dashed line rectangle in Figure 11. Inside that region it is assumed that $\rho(z)$ vertical profile is defined in terms of the Heaviside function $H(z)$ :

$$
\rho(z)=\rho_{+}\left[H(z)-H\left(z-t_{+}\right)\right]-\left|\rho_{-}\right|\left[H\left(z-h_{-}\right)-H\left(z-h_{-}-t_{-}\right)\right] .
$$

Equation (3) assumes that the positive SCD is at the ground, thus its height is $h_{+} \approx 0$, and has a thickness $t_{+}$, that can be assumed to be $t_{+} \approx 0$. Similarly, $h_{-}$and $t_{-}$stand for the height and thickness of the negative SCD at the bottom of the dust layer, respectively. The use of the Heaviside function assumes that the SCD is uniform inside the SCD thickness, $t_{-}$. Moreover, it is expected that $\rho_{+} \approx\left|\rho_{-}\right| \approx \rho_{0}$ and for that reason Equation (3) can be simplified to:

$$
\rho(z)=-\rho_{d}\left[H\left(z-h_{-}\right)-H\left(z-h_{-}-t_{-}\right)\right]
$$

It is important to mention that both the height, $h_{-}$, and thickness, $t_{-}$, of the space charge at the bottom of the dust layer are not necessarily equal to the height, $h_{d}$, and thickness, $t_{d}$, of the dust layer. Nevertheless, the space charge should be inside the dust layer and for that reason it is expected that: $h_{d}<h_{-}<h_{d}+t_{d}$ and $t_{-}<t_{d}$. According to the dust profile from BSC-DREAM8b model, Figure $3 \mathrm{e}$, it is possible to estimate the height and thickness of the dust layer on the $17^{\text {th }}$ July to be the $h_{d} \sim 2 \mathrm{~km}$ and $t_{d} \sim 2 \mathrm{~km}$. With these parameters the space charge height and thickness can be approximated to: $h_{-} \sim 2 \mathrm{~km}$ and $t_{-} \sim 0.1-1 \mathrm{~km}$. With the use of Equation (4), it is straightforward to integrate Equation (2) to estimate $F^{\prime}$ : 


$$
\int_{0}^{F^{\prime}} d F^{\prime}=\frac{1}{\varepsilon_{0}} \int_{0}^{h_{-}+t_{-}} \rho(z) d z=-\frac{\rho_{d}}{\varepsilon_{0}} \int_{h_{-}}^{h_{-}+t_{-}} d z
$$

After performing the integral, $F^{\prime}$ is simply given by: $F^{\prime}=-\rho_{d} t_{-} / \varepsilon_{0}$. This result can be used to estimate the SCD amplitude accumulated on the bottom of the dust layer from the $F$ ' values estimated above:

$$
\rho_{d}=\frac{\varepsilon_{0}}{t_{-}}\left|F^{\prime}\right|
$$

For the BEA case, considering that $t_{-}$varies from 0.1 to $1 \mathrm{~km}$, Equation (6) implies that the SCD amplitude varies around $\rho_{d} \approx 1.0-10.6 \mathrm{pCm}^{-3}$. For the EVO case, using the same range for $t_{-}$the SCD estimated by Equation (6) is $\rho_{d} \approx 3.4-34.4 \mathrm{pCm}^{-3}$. These are moderate SCD values, in reasonable agreement with the values observed experimentally (Nicoll et al., 2011); which point towards a fair explanation, with the discussed model, of the PG perturbations found during the Saharan dust event of $16^{\text {th }}$ and $17^{\text {th }}$ July 2014. Nevertheless, it should be mentioned that this is a simplified model and for that reason it relies on many assumptions implying several limitations; one of which is related to Equation (5) where there is the assumption that the space charges occupy semi-infinite planes in the $x$ and $y$ coordinates. This simplification tends to overestimate the real SCD that is expected to have a disc like shape.

After the desert dust has passed the region where the three sensors were installed it is reasonable to admit that the positive space charges (carried by lighter dust particles) have been transported away; while negative space charges (carried by heavier dust particles) might have been dispersed in the atmosphere. Those charges would be suspended in the atmosphere for one or two days after the dust event increasing atmospheric electric conductivity and through (quasi-static) Ohm's law implying a reduction of the PG. With sufficient time, atmospheric mixing would make them recombine with positive atmospheric ions (becoming neutral) and both electric conductivity and PG would recover their normal values. The increase of the electric conductivity under the influence of such negative space charge in relation to the normal case, where there are significantly less space charges, can be estimated by differentiating Ohm's law (assuming a constant air-Earth current, $J_{\mathrm{z}} \sim 2 \mathrm{pA} \mathrm{m-2):}$

$$
\Delta \sigma_{t}=-J_{z} \frac{\Delta F}{F_{n}^{2}} .
$$


In this equation $\Delta F=F_{\mathrm{s}}-F_{\mathrm{n}}, F_{\mathrm{s}}$ corresponds to $\mathrm{PG}$ under the space charge and $F_{\mathrm{n}}$ the $\mathrm{PG}$ for the normal situation. If the mean PG for the entire ALEX2014 campaign is used to estimate $F_{\mathrm{n}} \approx$ 81.0, 59.4 and $74.4 \mathrm{~V} / \mathrm{m}$ and the minimum of the lowess curves at the $19^{\text {th }}$ July is used to estimated $F_{\mathrm{s}} \approx 71.8,49.1$ and $50.1 \mathrm{~V} / \mathrm{m}$, respectively for BEA, AMI and EVO, Equation (7) gives $\Delta \sigma_{\mathrm{t}} \approx 2.8,5.8,8.8 \mathrm{fS} / \mathrm{m}$ for BEA, AMI and EVO. According to Harrison and Carslaw (2003) a typical estimation for atmospheric electric conductivity is $\sigma_{\mathrm{t}} \sim 13.3 \mathrm{fS} / \mathrm{m}$; what makes the estimations done for $\Delta \sigma_{\mathrm{t}}$ reliable.

\section{Conclusions}

Evidence of long-range Saharan dust electrification is found in PG measurements carried out by a triangular array of stations in Southern Portugal. This occurred during the dust event of $16^{\text {th }}$ $17^{\text {th }}$ July 2014, which coincided with the ALEX2014 campaign. Two signatures of dust electrification have been found in the PG data: (i) significant magnitude short time-scale oscillations of the PG at two of the stations; (ii) mid time-scale suppression of the PG at the three stations. A formulation was developed to explain these observations assuming that the air-Earth electrical current creates a bipolar space charge distribution inside of the dust layer. Values of space charge density amplitude are found to be around $\rho \sim 20 \mathrm{pCm}^{-3}$; consistent with previously reported values in the literature. The importance of using arrays of PG sensors, instead of single site measurements, is hereby demonstrated.

\section{Acknowledgements}

Experiments were accomplished during the field campaign funded by FCT (Portuguese Science and Technology Foundation) and FEDER-COMPETE: ALEX 2014 (EXPL/GEOMET/1422/2013): FCOMP-01-0124-FEDER-041840. The work was co-funded by the European Union through the European Regional Development Fund, COMPETE 2020, through ICT (UID/GEO/04683/2013): POCI-01-0145-FEDER-007690. SNP is grateful for the support by FCT through the post-doc grant: SFRH/BPD/81132/2011 and KAN acknowledges a NERC Independent Research Fellowship (NE/L011514/1). The authors are deeply grateful to John Chubb for his insightful discussions over this topic. HGS personally acknowledges his friendship and kindness. He shall be missed. Maintenance work of the field-mill installed at Beja Air-base 
done by the Meteorology Department (Carlos Policarpo and his team) is here truly recognized. The work of two anonymous reviewers is truly acknowledged. 


\section{References}

Angstrom, A. (1924) Solar and Terrestrial Radiation. Quarterly Journal of the Royal Meteorological Society, 50, 121-126.

Basart, S., Pérez, C., Nickovic, S., Cuevas, E., and Baldasano, J.M. (2012). Development and evaluation of the BSC-DREAM8b dust regional model over Northern Africa, the Mediterranean and the Middle East. Tellus B, 64, 18539.

Calle, C.I., Buhler, C.R., McFall, J.L., and Snyder, S.J. (2009). Particle removal by electrostatic and dielectrophoretic forces for dust control during lunar exploration missions, Journal of Electrostatics 67, 89-92.

Chalmers, J. A. (1967), Atmospheric Electricity, 2nd ed., Pergamon, Oxford, U. K.

Chubb, J. (2015) Comparison of atmospheric electric field measurements by a pole mounted fieldmeter and by a horizontal wire antenna. Journal of Electrostatics 73, 1-5. DOI: 10.1016/j.elstat.2014.10.003.

Chubb, J. (2014). The measurement of atmospheric electric fields using pole mounted electrostatic fieldmeters. Journal of Electrostatics 72, 295-300. DOI: 10.1016/j.elstat.2014.05.002

Conceição, R. and Silva, H.G. (2015). Simulations of the Global Electrical Circuit coupled to local Potential Gradient measurements, Journal of Physics: Conference Series 646, 012017.

Conceição, R., Melgão, M., Silva, H.G., Nicoll, K., Harrison, R.G., and Reis, A.H. (2015). Transport of the smoke plume from Chiado's fire in Lisbon (Portugal) sensed by atmospheric electric field measurements. Air Quality, Atmosphere \& Health 8. DOI: 10.1007/s11869-0150337-4.

Delory, G.T., Farrell, W.M., Atreya, S.K., Renno, N.O., Wong, A.-S., Cummer, S.A., Sentman, D.D., Marshall, J.R., Rafkin, S.C.R., Catling, D.C. (2006). Oxidant Enhancement in Martian Dust Devils and Storms: Storm Electric Fields and Electron Dissociative Attachment. Astrobiology 6(3), 451-462.

Duff, N. and Lacks, D.J., (2008). Particle dynamics simulations of triboelectric charging in granular insulator systems. J. Electrost. 66, 51.

Engelstaedter, S., Tegen, I., and Washington, R. (2006). North African dust emissions and transport. Earth-Sci. Rev. 79 73-100. 
Esposito, F., Molinaro, R., Popa, C.I., Molfese, C., Cozzolino, F., Marty, L., Taj-Eddine, K., Di Achille, G., Franzese, G., Silvestro, S., and Ori, G.G. (2016). The role of the atmospheric electric field in the dust-lifting process, Geophys. Res. Lett., 43.

Esposito, F., Debei, S., Bettanini, C., Molfese, C., Arruego Rodriguez, I., Colombatti, G., Harri, A. M., Montmessin, F., Wilson, C., Aboudan, A., Abbaki, S., Apestigue, V., Bellucci, G., Berthelier, J. J., Brucato, J. R., Calcutt, S. B., Cortecchia, F., Cucciarrè, F., Di Achille, G., Ferri, F., Forget, F., Friso, E., Genzer, M., Haukka, H., Jimènez, J. J., Jimènez, S., Josset, J. L., Karatekin, O., Landis, G., Lorenz, R., Marchetti, E., Martinez, J., Marty, L., Mennella, V., Möhlmann, D., Moirin, D., Molinaro, R., Palomba, E., Patel, M., Pommereau, J. P., Popa, C. I., Rafkin, S., Rannau, P., Renno, N. O., Schipani, P., Schmidt, W., Segato, E., Silvestro, S., Simões, F., Spiga, A., Valero, F., Vázquez, L., Vivat, F., Witasse, O., Mugnuolo, R., and Pirrotta, S. (2014). The DREAMS Experiment of the ExoMars 2016 Mission for the Study of Martian Environment During the Dust Storm Season, Eighth International Conference on Mars, held July 14-18, 2014 in Pasadena, California. LPI Contribution No. 1791, p. 1246.

Ette, A.I. (1970). The effect of the Harmattan dust on atmospheric electric parameters. J. Atmos. Terr. Phys. 33 295-300.

Freier, G.D. (1960). The electric field of a large dust devil, J. Geophys. Res., 65(10), 3504.

Grinsted, A., J. C. Moore, S. Jevrejeva (2004), Application of the cross wavelet transform and wavelet coherence to geophysical time series, Nonlin. Process. Geophys., 11, 561566.

Harrison, R. G. (2013). The Carnegie Curve. Surveys in Geophysics, 34, 209-232.

Harrison, R.G. and Carslaw, K.S. (2003). Ion-aerosol-cloud processes in the lower atmosphere, Reviews of Geophysics, 41(3), 1012.

Holben, B.N., Eck, T.F., Slutsker, I. et al. (1998). AERONET - A federated instrument network and data archive for aerosol characterization. Remote Sensing of Environment, 66 (1), 1-16. DOI: 10.1016/S0034-4257(98)00031-5

Inculet, I.I., Castle, G.S.P., Aartsen, G. (2006). Generation of bipolar electric fields during industrial handling of powders. Chem. Eng. Sci. 61, 2249-2253.

Kamra, A. (1972). Measurements of the electrical properties of dust storms. J. Geophys. Res. 77 5856-69. 
Lopes, F., Silva, H.G., Bárias, S., and Barbosa, S.M. (2015) Preliminary results on soil-emitted gamma radiation and its relation with the local atmospheric electric field at Amieira (Portugal). Journal of Physics: Conference Series 646, 012015. DOI: 10.1088/1742-6596/646/1/012015.

Lopes, F., Silva, H.G., Salgado, R., Potes, M., Nicoll, K., and Harrison, G. (2016). Atmospheric Electrical Field measurements near a Fresh Water Reservoir and the formation of the Lake Breeze, Tellus A 68, 31592 (2016); DOI: 10.3402/tellusa.v68.31592

Nicoll, K.A., and Harrison, R.G. (2010). Experimental determination of layer cloud edge charging from cosmic ray ionisation. Geophys. Res. Lett. 37, L13802.

Nicoll, K.A., Harrison, R.G., and Ulanowski, Z. (2011). Observations of Saharan dust layer electrification, Environ. Res. Lett. 6, 014001.

Obregón, M.A., Pereira, S., Salgueiro, V., Costa, M.J., Silva, A.M., Serrano, A., and Bortoli, D. (2015). Aerosol radiative effects during two desert dust events in August 2012 over the Southwestern Iberian Peninsula. Atmospheric Research 153, 404-415.

Pérez, C., Nickovic, S., Baldasano, J.M., Sicard, M., Rocadenbosch, F., and Cachorro, V.E. (2006a). A long Saharan dust event over the western Mediterranean: Lidar, Sun photometer observations, and regional dust modeling. Journal of Geophysical Research, Vol. 111, D15214.

Pérez, C., Nickovic, S., Pejanovic, G., Baldasano, J.M. and Özsoy, E. (2006b). Interactive dustradiation modeling: A step to improve weather. Journal of Geophysical Research, Vol. 111, D16206.

Preißler, J., F. Wagner, S. N. Pereira, and J. L. Guerrero-Rascado (2011), Multi-instrumental observation of an exceptionally strong Saharan dust outbreak over Portugal, J. Geophys. Res., 116, D24204, doi:10.1029/2011JD016527.

Reiter, R. (1992). Phenomena in Atmospheric and Environmental Electricity. Developments in Atmospheric Sciences, Elsevier (562 pp.).

Rycroft, M. J., Israelsson, S. and Price, C. (2000). The global atmospheric electric circuit, solar activity and climate change Jour. Atmosph. Solar-Ter. Phys. 62 1563-1576.

Rudge, W.A.D. (1913). Atmospheric Electrification during South African Dust Storms. Nature 91, 31-32.

Sarver, T., Qaraghuli, A.A., and Kazmerski, L.L. (2013). A comprehensive review of the impact of dust on the use of solar energy: History, investigations, results, literature, and mitigation approaches. Renewable and Sustainable Energy Reviews 22, 698. 
Siingh, D., Singh, R.P., Gopalakrishnan, V., Selvaraj, C., and Panneerselvam, C. (2013). Fairweather atmospheric electricity study at Maitri (Antarctica). Earth Planets Space 65, 1541-1553.

Stein, A.F., Draxler, R.R., Rolph, G.D., Stunder, B.J.B., Cohen, M.D., and Ngan, F. (2015). NOAA's Hysplit atmospheric transport and dispersion modeling system. Bull. Amer. Meteor. Soc., 96, 2059-2077.

Tacza, J., Raulin, J.-P., Macotela, E., Norabuena, E., Fernandez, G., Correia, E., Rycroft, M.J., and Harrison, R.G. (2014). A new South American network to study the atmospheric electric field and its variations related to geophysical phenomena. J. Atmos. Sol-Terr. Phys., 120, 70-79. DOI: 10.1016/j.jastp.2014.09.001.

Torrence, C., and Compo, G.P. (1998). A practical Guide to Wavelet Analysis. Bull. Amer. Meteor. Soc. 79(1), 61-78.

Ulanowski, Z., Bailey, J., Lucas, P.W., Houghm J.H., Hirst, E. (2007) Alignment of atmospheric mineral dust due to electric field. Atmos. Chem. Phys. 7 6161-73.

Williams, E., Nathou, N., Hicks, E., Pontikis, C., Russell, B., Miller, M., and Bartholomew, M.J. (2009). The electrification of dust-lofting gust fronts ('haboobs') in the Sahel, Atmos. Res., 91, 292-298.

Winker, D. M., W. H. Hunt, and M. J. McGill (2007), Initial performance assessment of CALIOP, Geophys. Res. Lett., 34, L19803, doi:10.1029/2007GL030135. 
Figure 1. (upper-panel) Geographic location of the three sites used for measurements of atmospheric electric potential gradient: Évora $\left(\mathrm{EVO}, 38.50^{\circ} \mathrm{N}, 7.91^{\circ} \mathrm{W}\right)$, Amieira (AMI, $38.27^{\circ}$ $\left.\mathrm{N}, 7.53^{\circ} \mathrm{W}\right)$ and Beja $\left(\mathrm{BEA}, 38.07^{\circ} \mathrm{N}, 7.93^{\circ} \mathrm{W}\right)$. (lower-panels) Hysplit backward trajectories for EVO, AMI and BEA on: (a) $15^{\text {th }}$ July 2014; (b) $16^{\text {th }}$ July 2014; (c) $17^{\text {th }}$ July 2014 ; (d) $18^{\text {th }}$ July 2014 Red trajectories correspond to particles arriving at altitudes of $2 \mathrm{~km}$, blue ones to $2.5 \mathrm{~km}$ and green ones to $3 \mathrm{~km}$. The white rectangle represents the zoom-in appearing in the upperpanel.

Figure 2. (a) Aerosol optical depth, at $440 \mathrm{~nm}$, and Angstrom Exponent measured at Évora during July 2014; (b) Attenuated backscatter profiles from CALIOP (Cloud Aerosol Lidar with Orthogonal Polarization) aboard of CALIPSO (Cloud-Aerosol Lidar and Infrared Pathfinder Satellite Observations) for the dawn of $18 \mathrm{t}^{\mathrm{h}}$ July. The inset shows the satellite path along which the profile was taken.

Figure 3. BSC-DREAM8b maps of total dust load $\left(\mathrm{g} / \mathrm{m}^{3}\right)$ for: (a) $15^{\text {th }} \mathrm{July} 2014$; (b) $16^{\text {th }} \mathrm{July}$ 2014; (c) $17^{\text {th }}$ July 2014; (d) $18^{\text {th }}$ July 2014; all at 12:00 UTC. The vertical dust profiles appear on panel (e) in which the black profile corresponds to $15^{\text {th }}$ July and the fading grey runs from the $16^{\text {th }}$ to $18^{\text {th }}$ July.

Figure 4. Daily variation of the PG for the ALEX2014 campaign at BEA station. The thick black lines in the plots represent the lowess smoothed mean daily FW PG for the all campaign. The dust event starts on $16^{\text {th }}$ July and ends on the $17^{\text {th }}$ July (highlight by dark blue rectangles). Dark red rectangles mark the day before and after the dust event.

Figure 5. Daily variation of the PG for the ALEX2014 campaign at AMI station. The thick black lines in the plots represent the lowess smoothed mean daily FW PG for the all campaign. The dust event starts on $16^{\text {th }}$ July and ends on the $17^{\text {th }}$ July (highlight by dark blue rectangles). Dark red rectangles mark the day before and after the dust event. 
Figure 6. Daily variation of the PG for the ALEX2014 campaign at EVO station. The thick black lines in the plots represent the lowess smoothed mean daily FW PG for the all campaign. The dust event starts on $16^{\text {th }}$ July and ends on the $17^{\text {th }}$ July (highlight by dark blue rectangles). Dark red rectangles mark the day before and after the dust event.

Figure 7. Number of local minima of the PG daily curves, marked with red dots, and Relative Std (\%), marked with blue dots, respectively for: (a) BEA; (b) AMI; (c) EVO. The left y-axis (in red) stands for the Number of local minima and the right one (in blue) for the Relative Std. The dark red horizontal lines highlight the Number of local minima and the dark blue the Relative Std both for the $17^{\text {th }}$ July 2014 .

Figure 8. PG at BEA: (a) raw data (back solid line represents a robust lowess smoothing); (b) wavelet periodogram (1-hour averaged). The vertical dashed line in both panels represents the $16^{\text {th }}$ July 2014 desert dust event. Gaps correspond to missing data.

Figure 9. PG at AMI: (a) raw data (back solid line represents a robust lowess smoothing); (b) wavelet periodogram (1-hour averaged). The vertical dashed line in both panels represents the $16^{\text {th }}$ July 2014 desert dust event. Gaps correspond to missing data.

Figure 10. PG at EVO: (a) raw data (back solid line represents a robust lowess smoothing); (b) wavelet periodogram (1-hour averaged). The vertical dashed line in both panels represents the $16^{\text {th }}$ July 2014 desert dust event. Gaps correspond to missing data.

Figure 11. Schematic diagram of the charge model to explain the observations: (a) diagram for clean aerosol conditions; (b) diagram for a desert dust event. 


\section{Supplementary material}

Figure S1. Animated Graphics Interchange Format (GIF) representation of the SEVIRI Image Data from METEOSAT for 15th-18th of July. The representation is made with RGB channels and the indication of time is on UTC.

Figure S2. Daily variation of the GHI for the ALEX2014 campaign at EVO station. The thick black lines in the plots represent the lowess smoothed mean daily GHI for the six selected days. Dark grey rectangles mark those days. 
Click here to download high resolution image
Clice
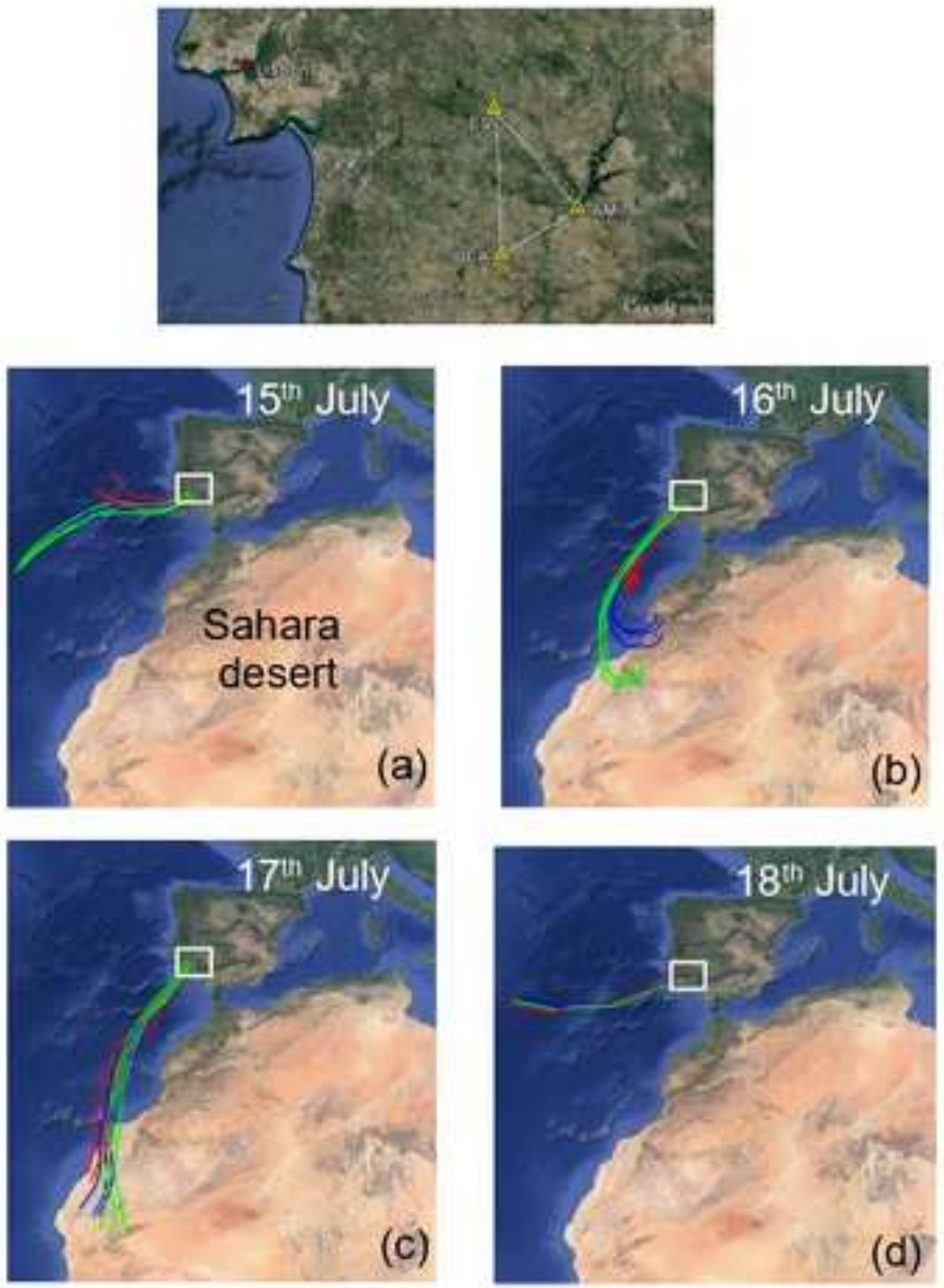


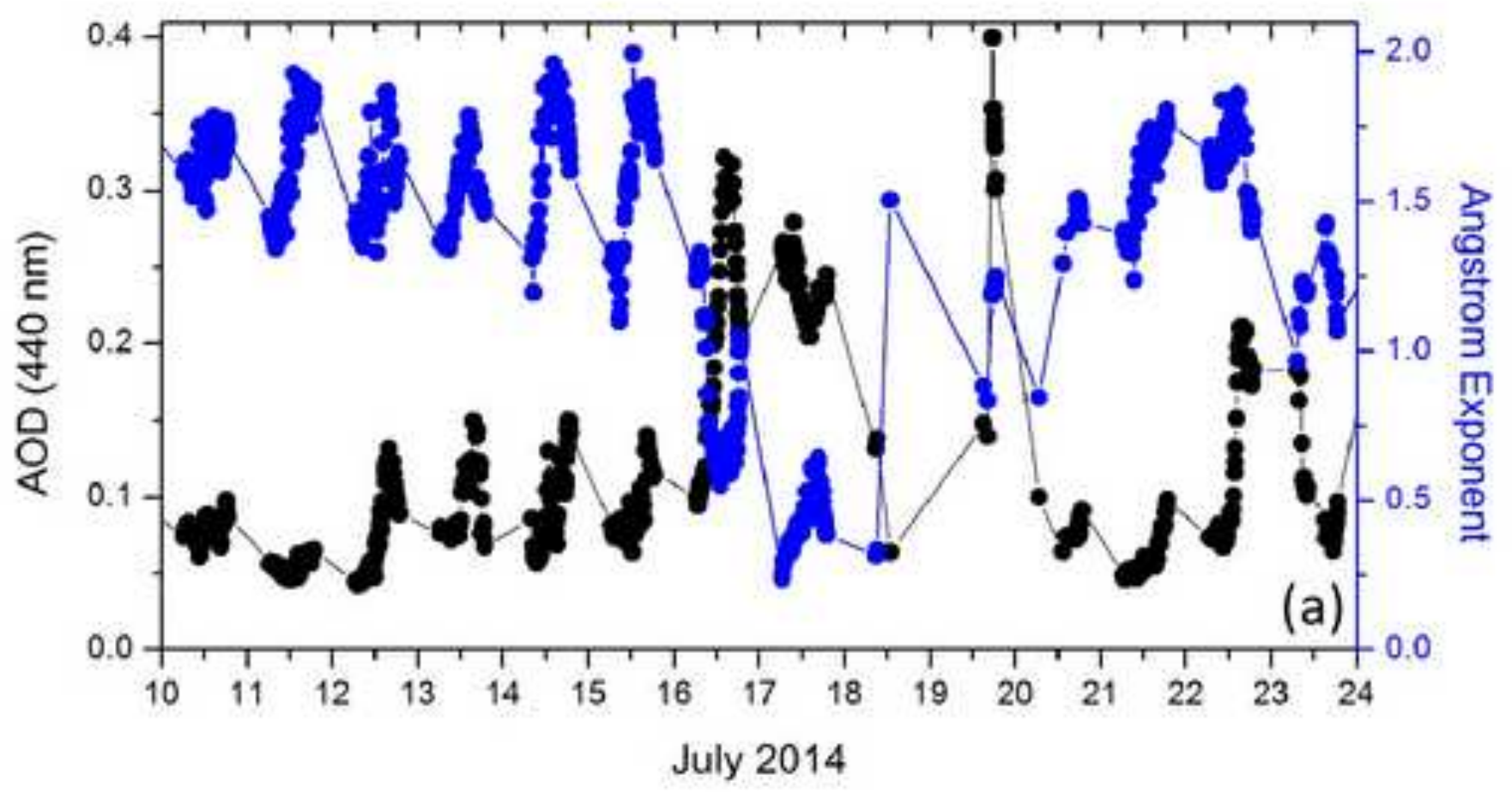

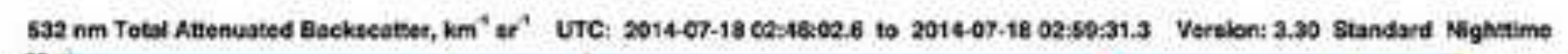

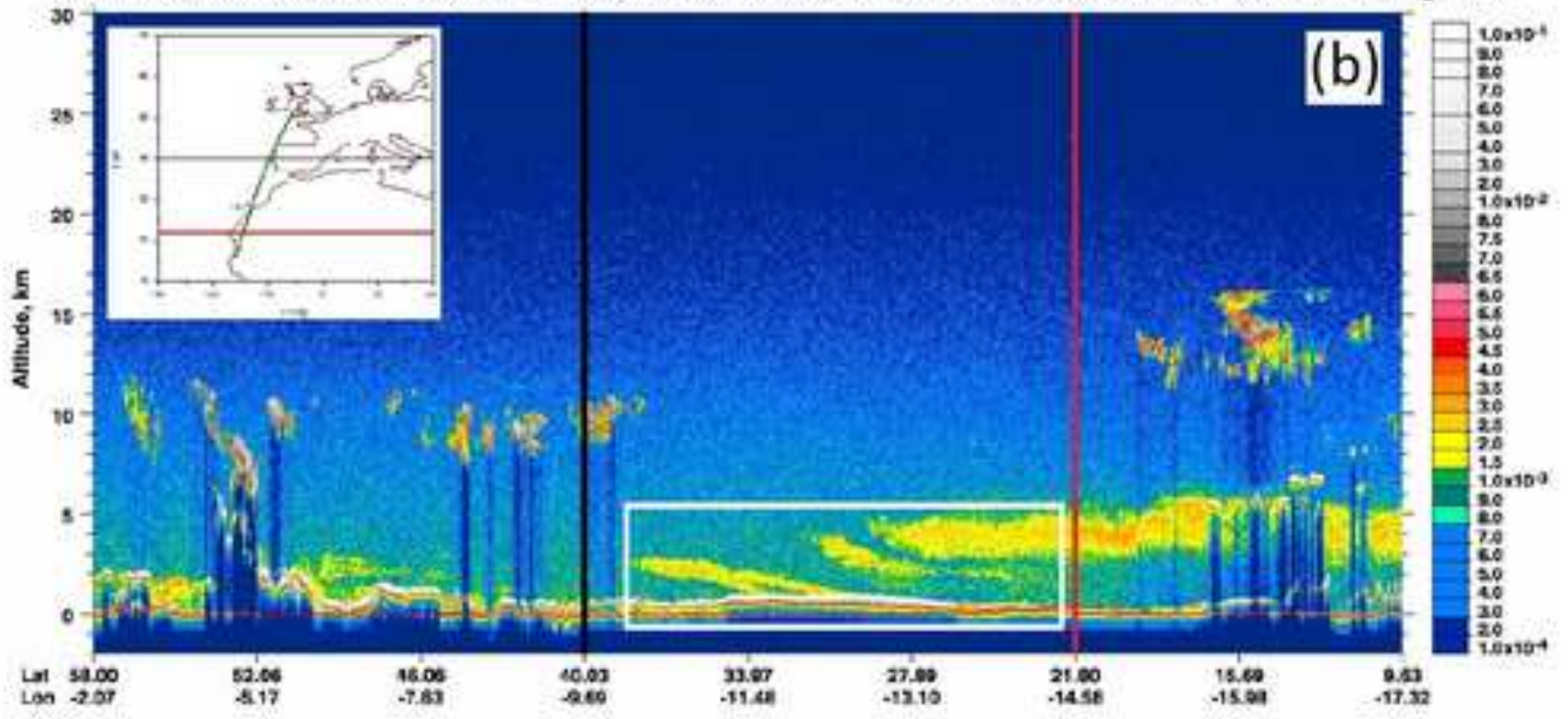




\section{Figure}

Click here to download high resolution image
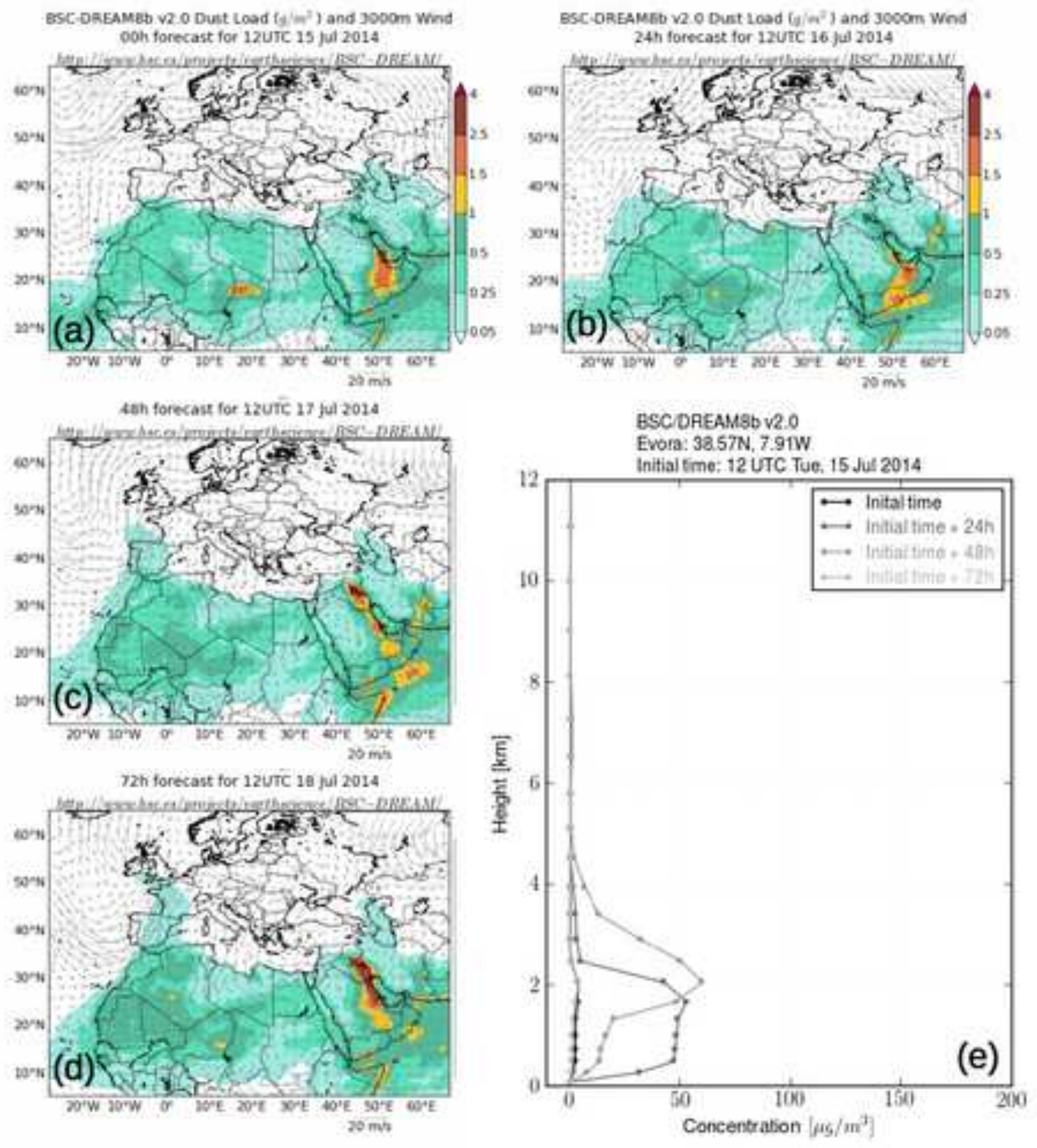

(e)

$$
20 \mathrm{~min}^{2}
$$




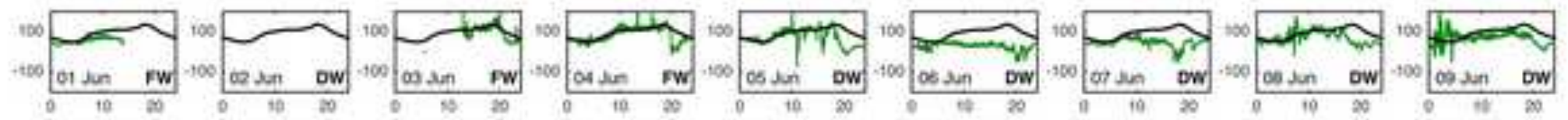

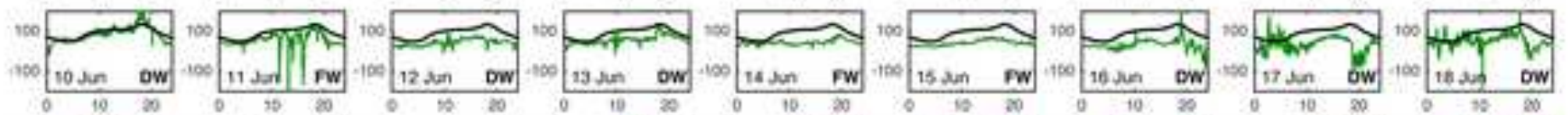

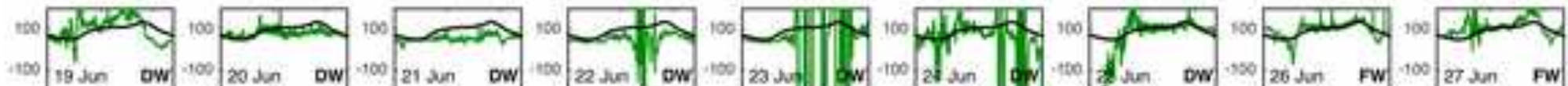

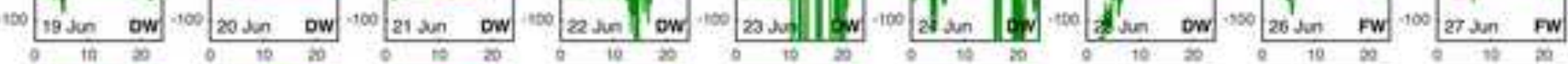

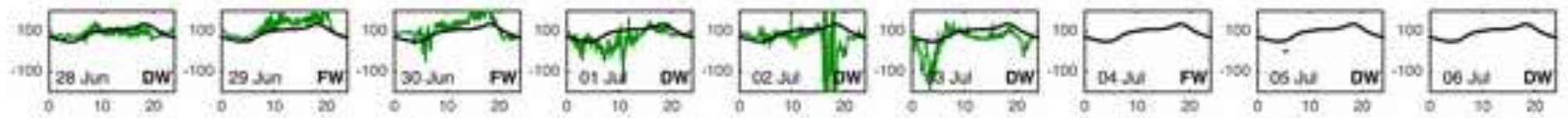
$\sum_{\mathrm{C}}^{\mathrm{E}}$

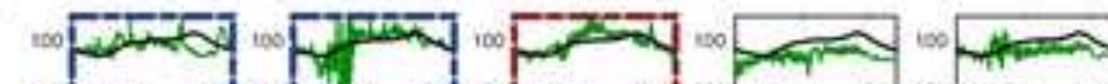

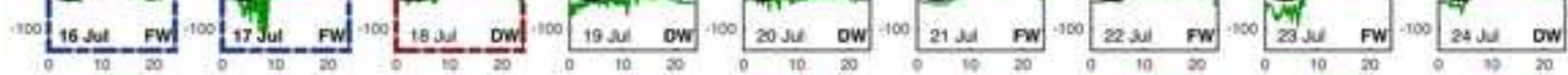
-1000 ow

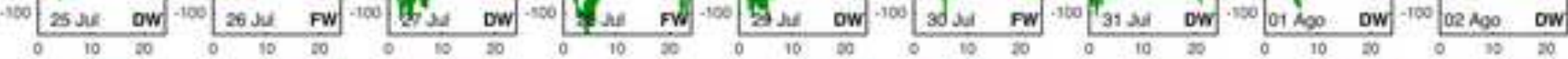

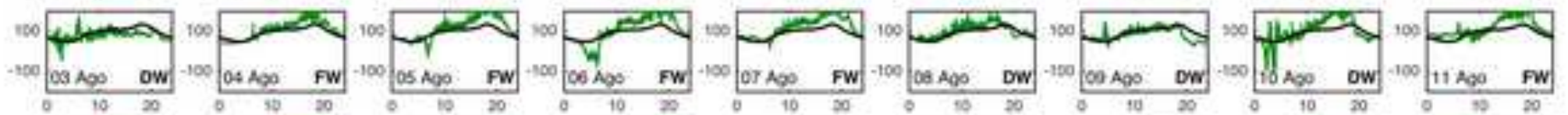

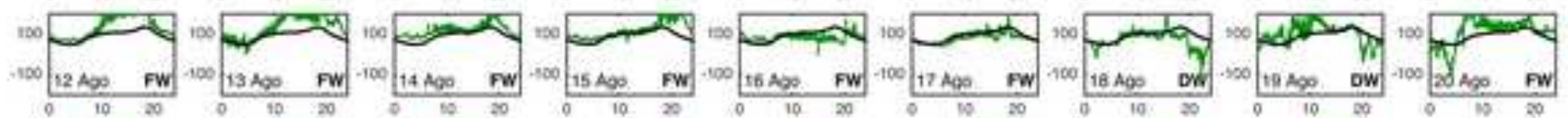

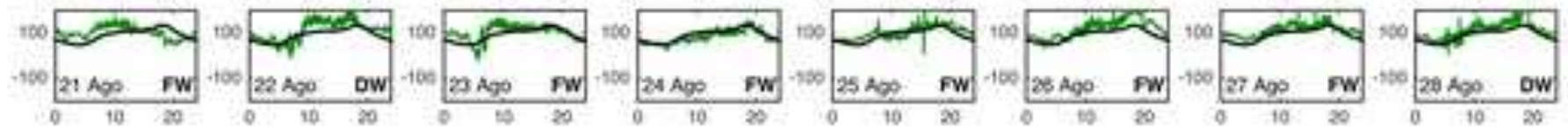




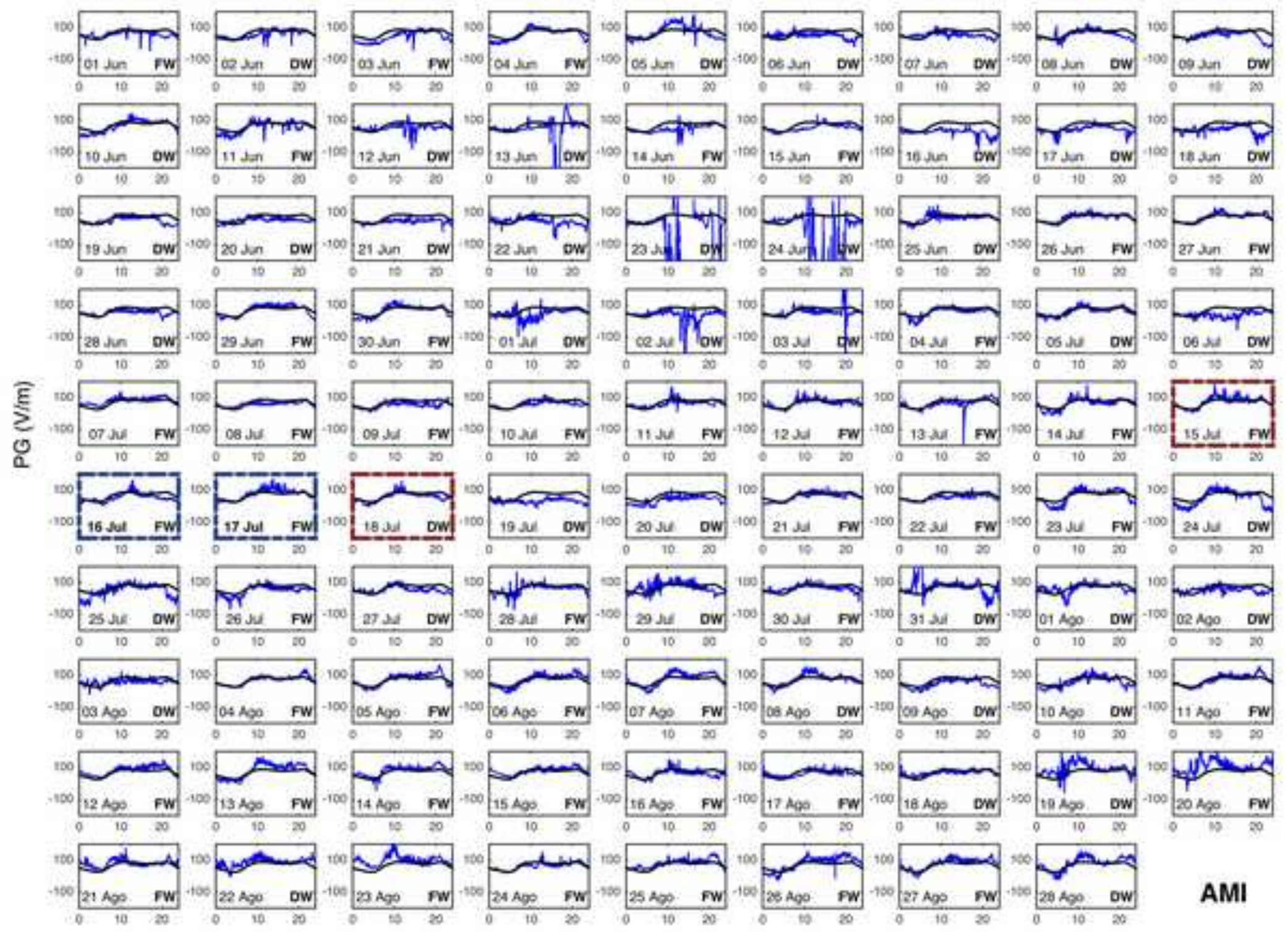

Time (hour) 


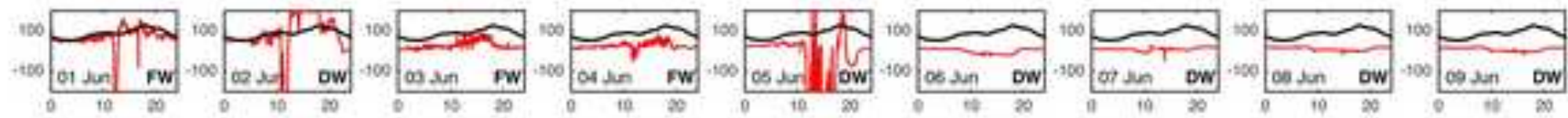
年

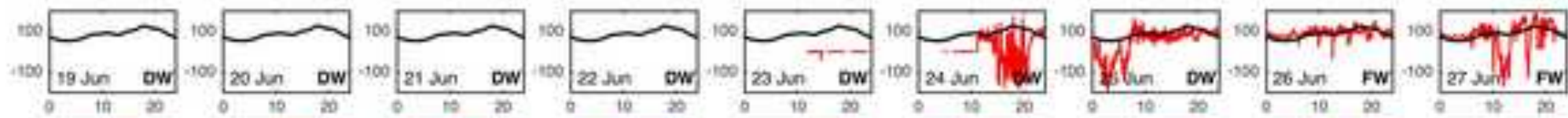

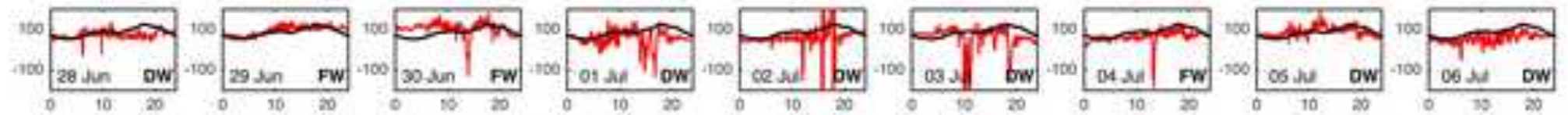

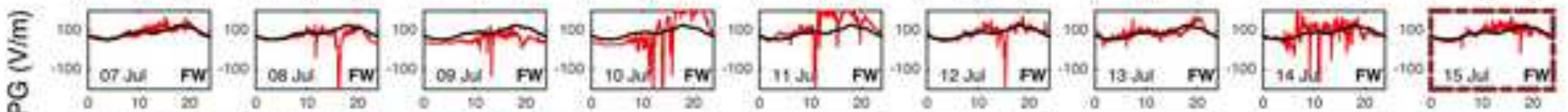

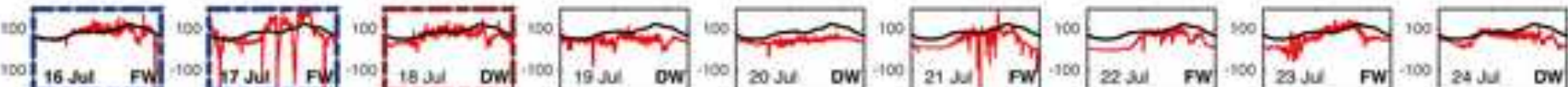

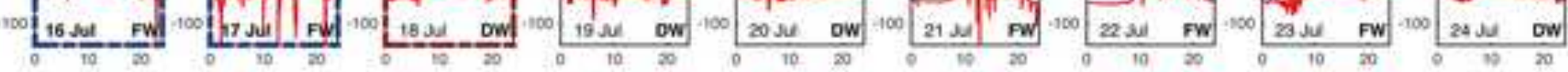

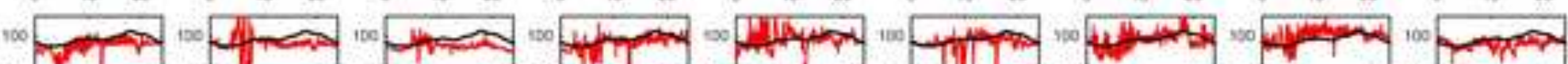

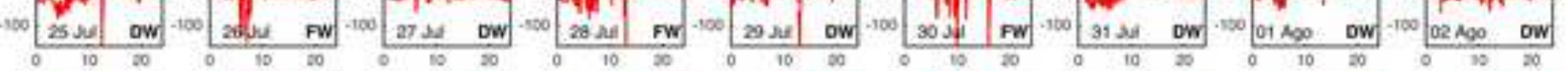

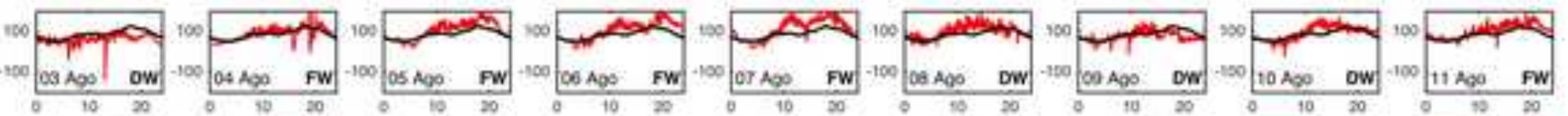

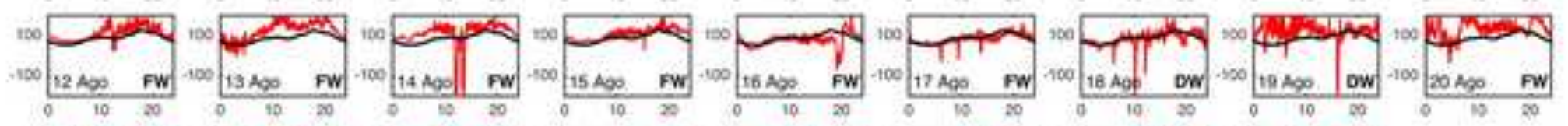

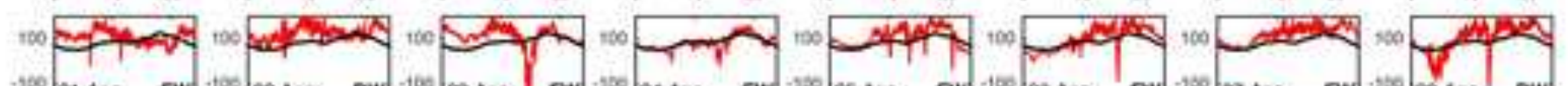

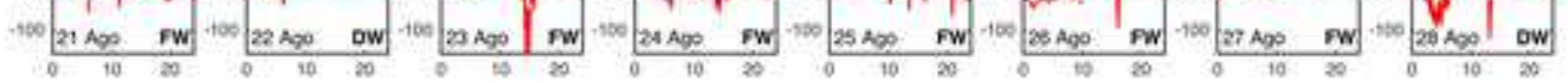



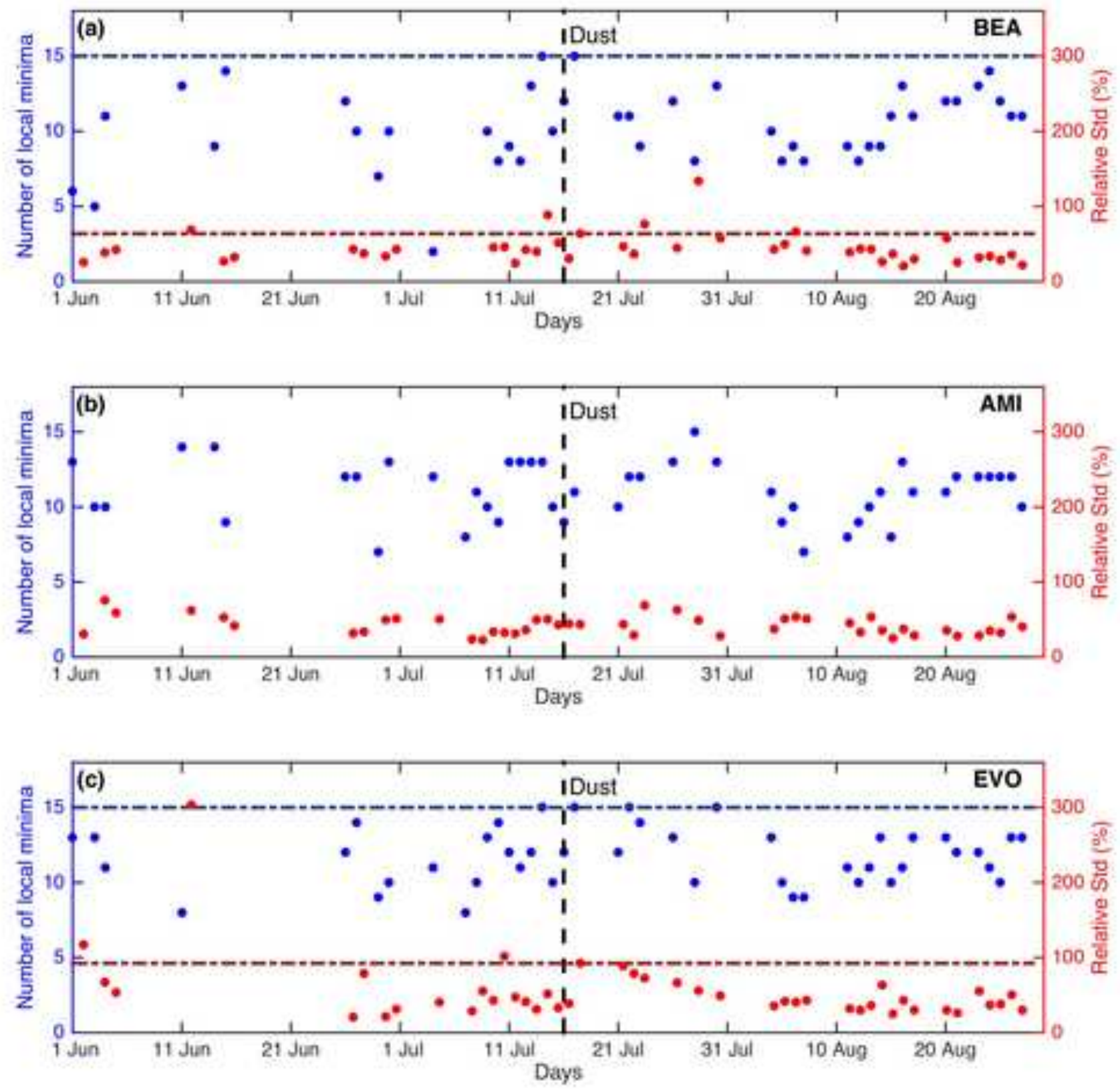
(a) Raw data

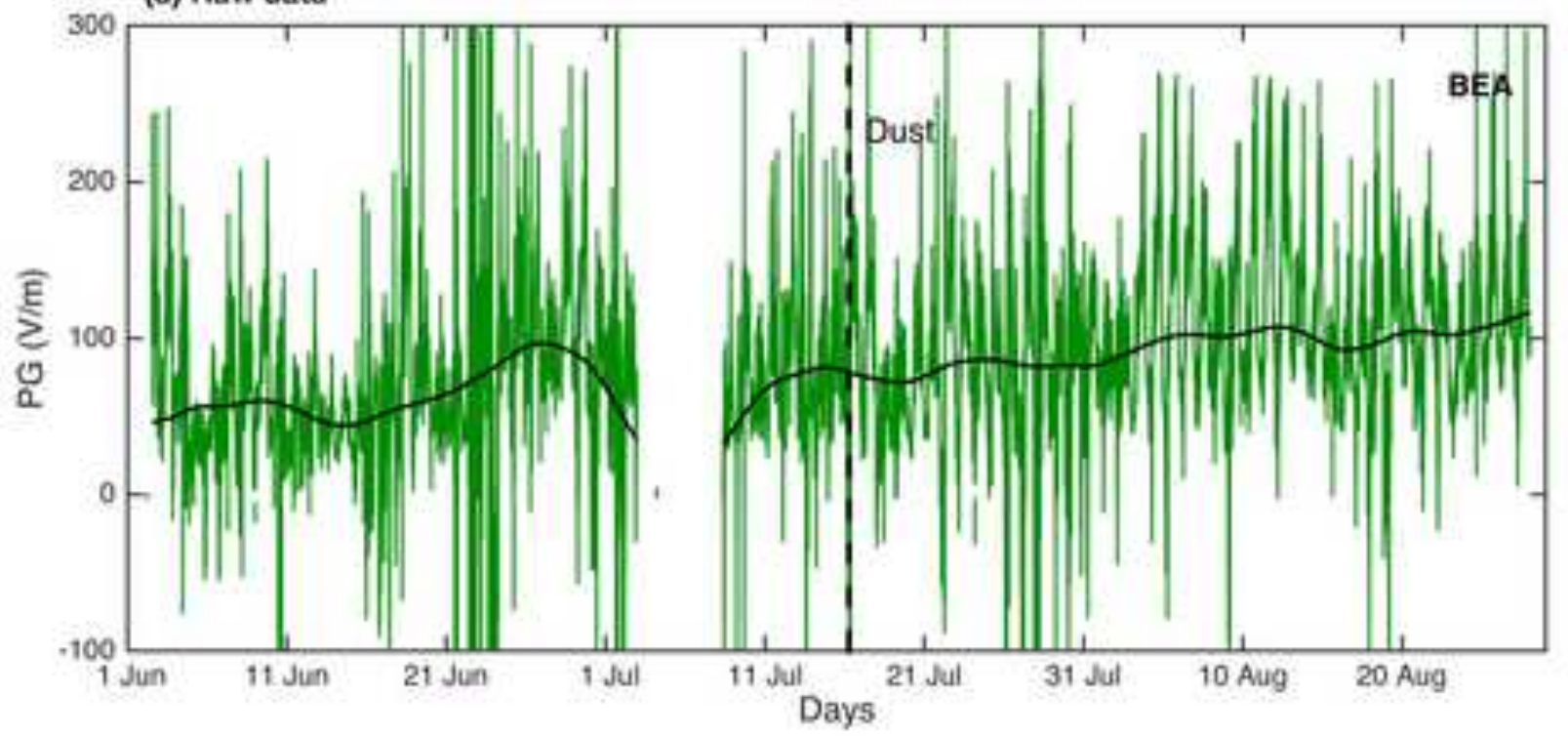

(b) Wavelet Periodogram

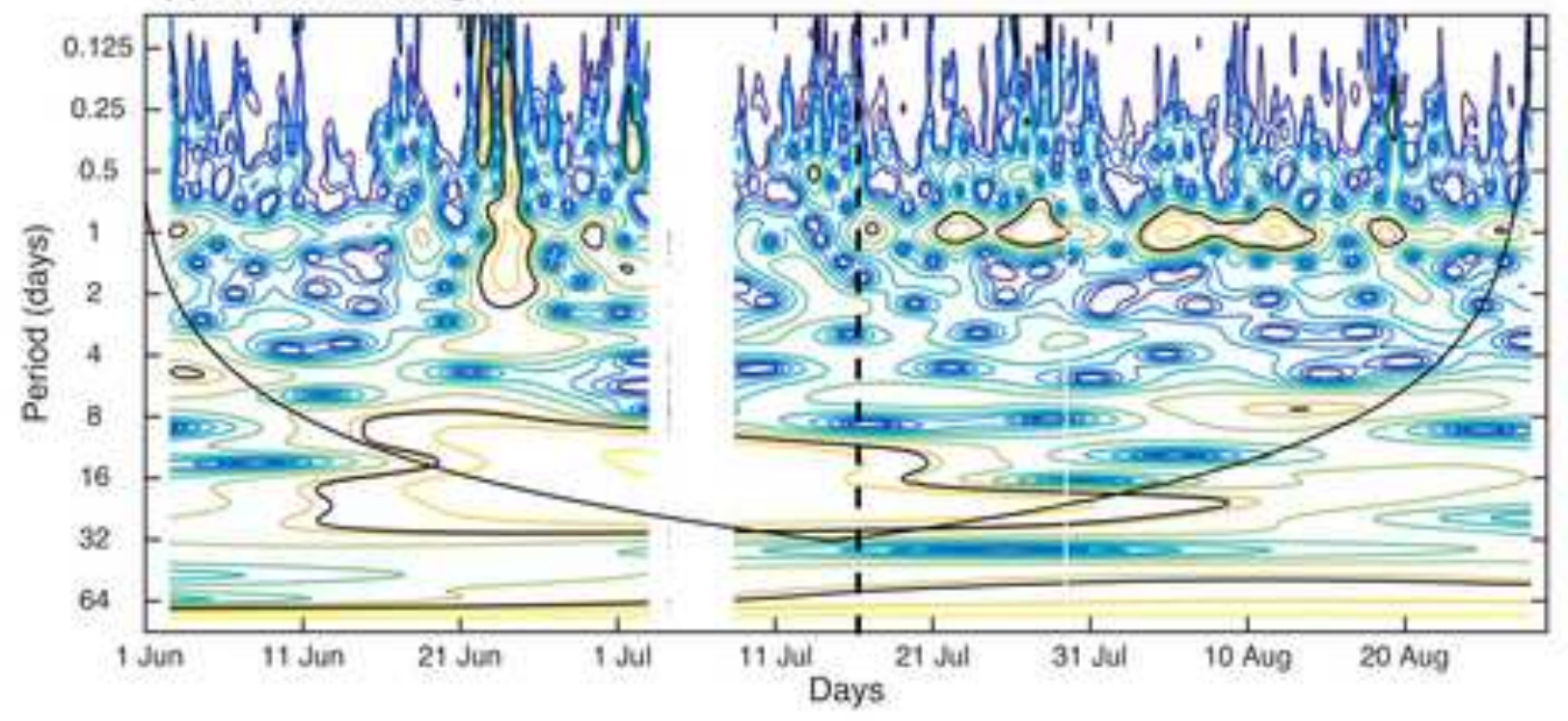


(a) Raw data

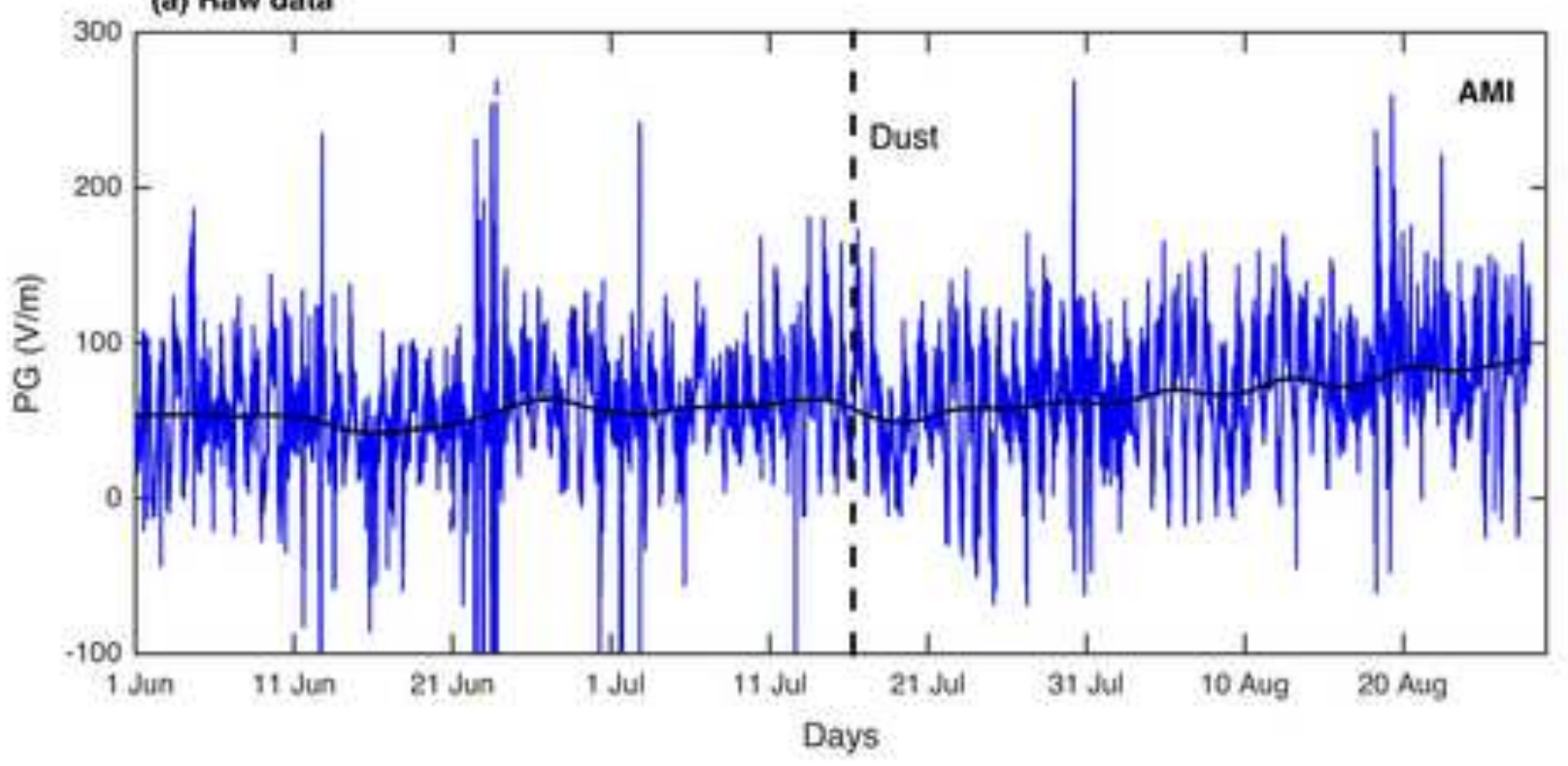

(b) Wavelet Periodogram

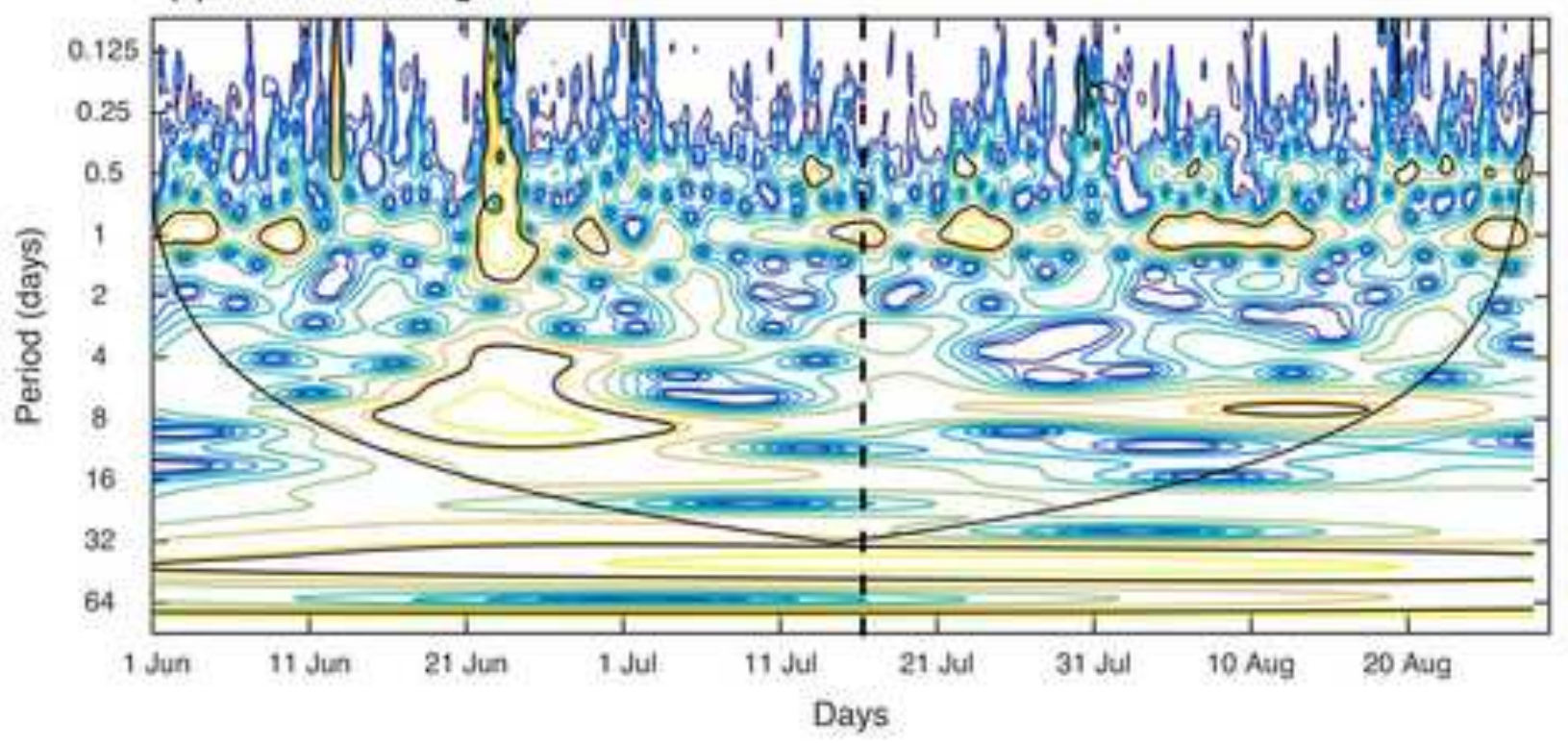




\section{Figure}

Click here to download high resolution image

(a) Raw data

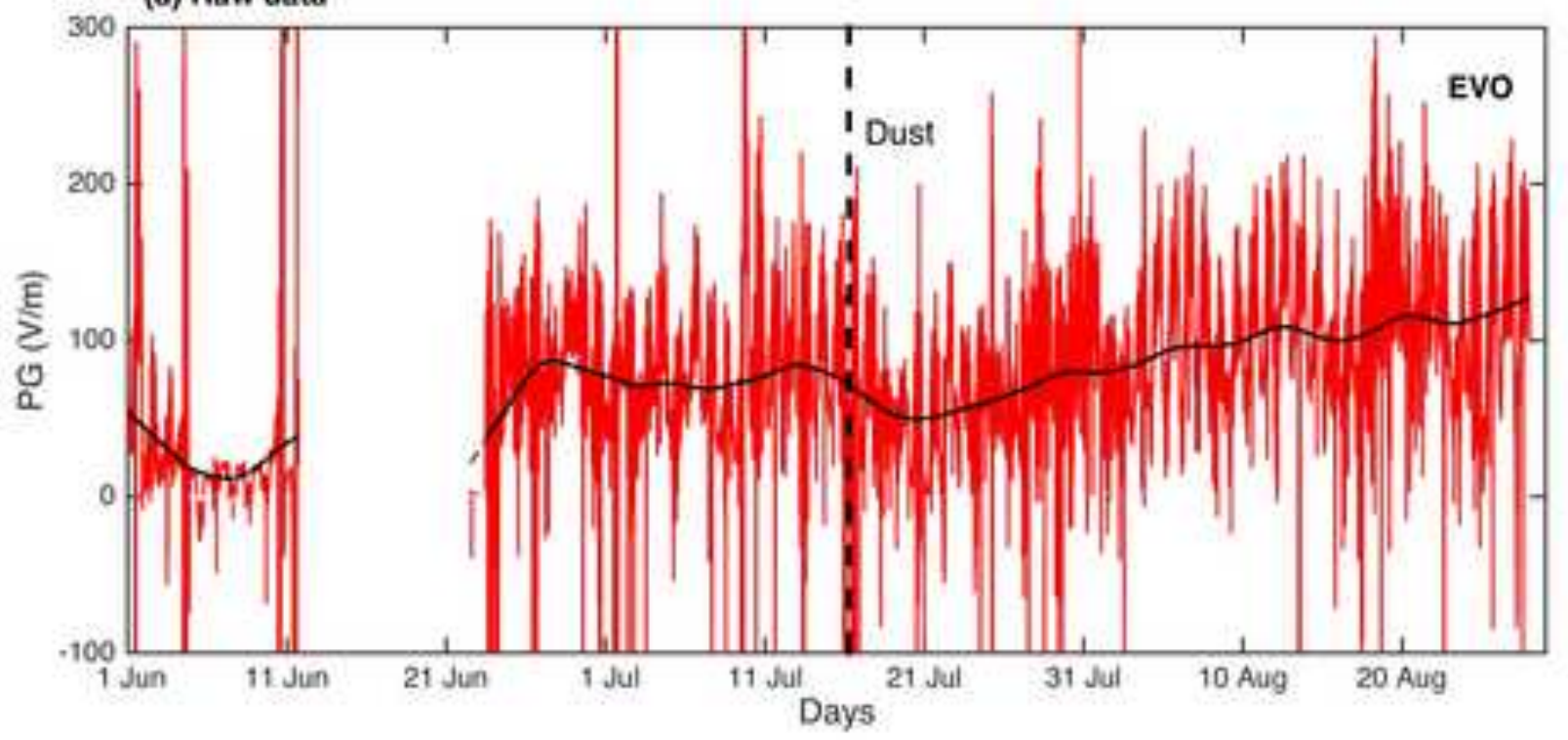

(b) Wavelet Periodogram

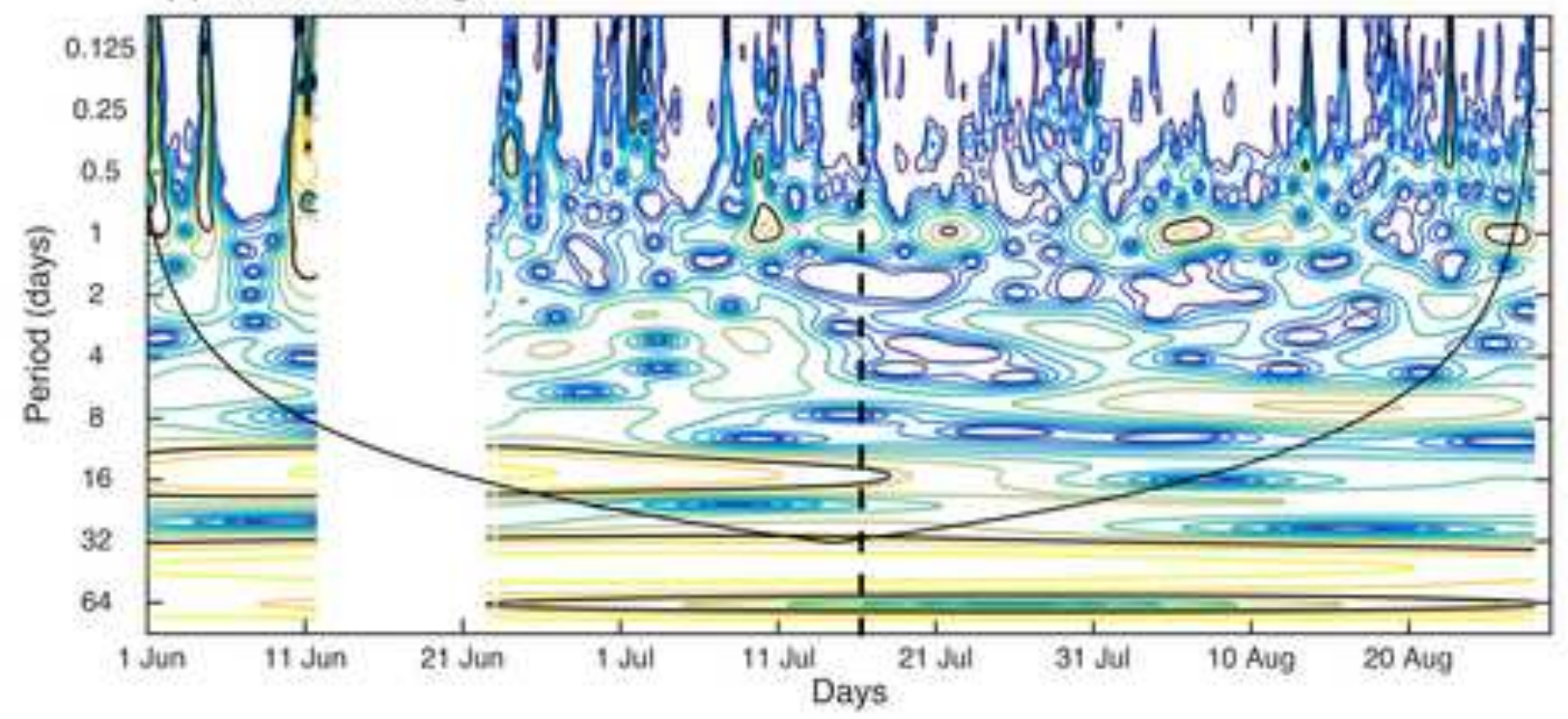




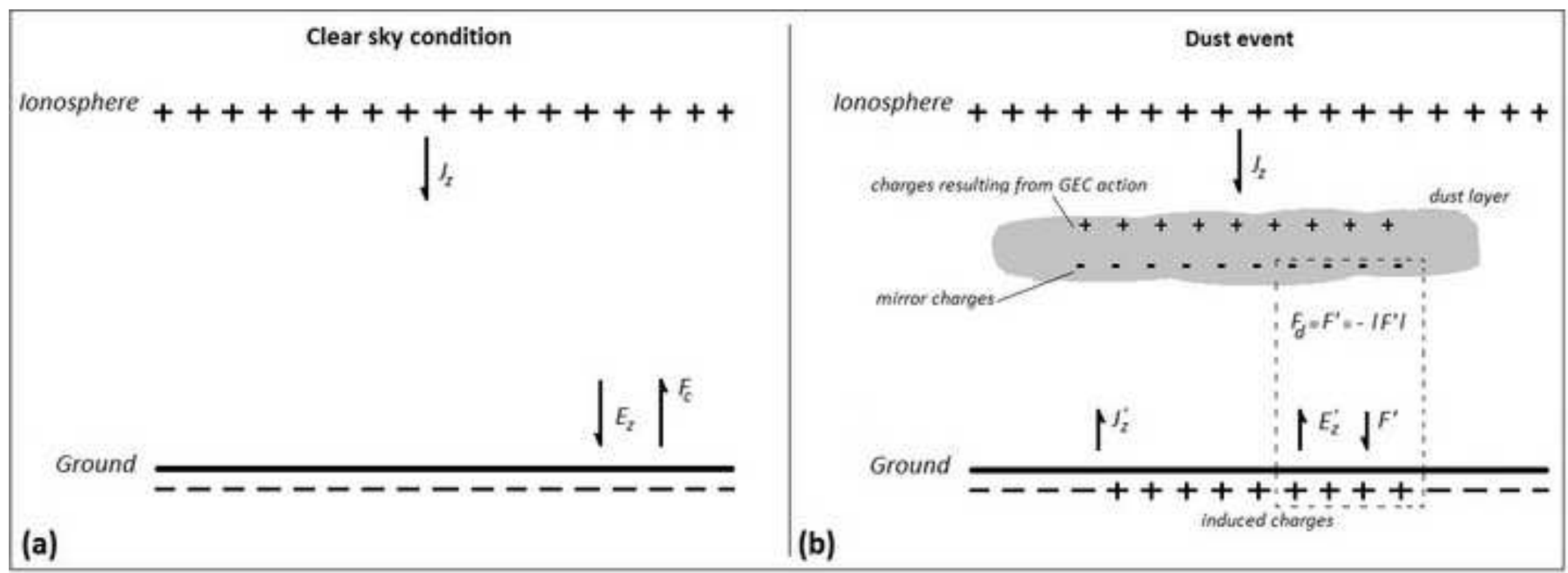


Suplementary material
Click here to download high resolution image

2014-07-15 03642

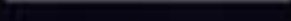




\section{EVO}

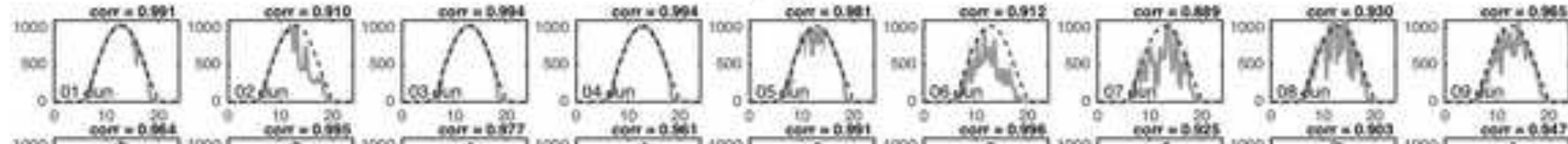

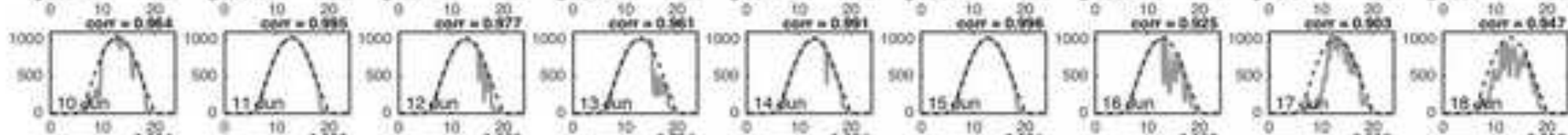
[19:

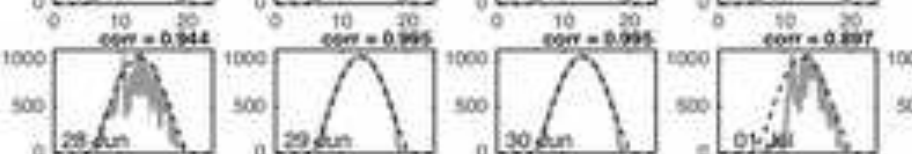
o is 0 [ats is a leakn to
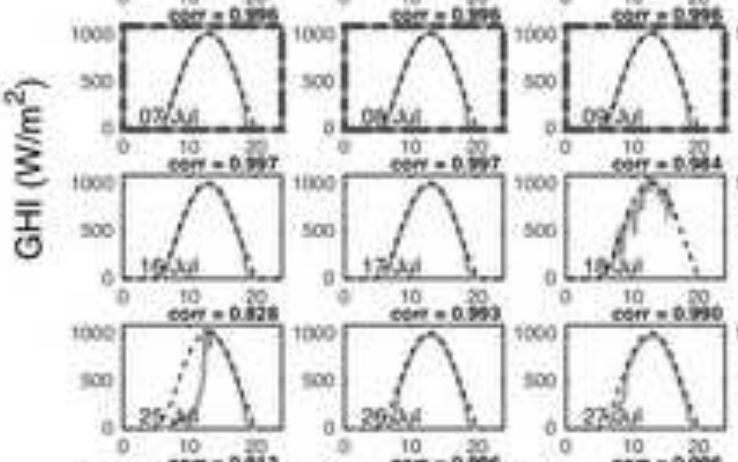

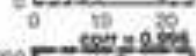
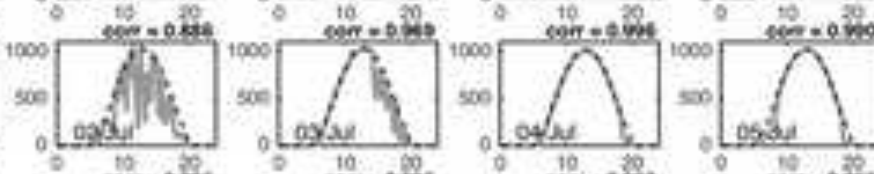

$\sin _{1000}^{1000}$
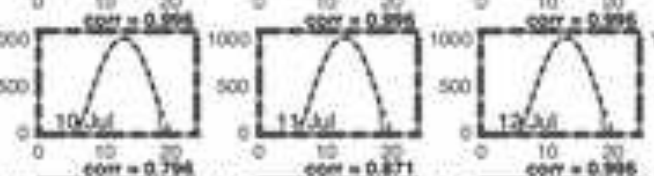

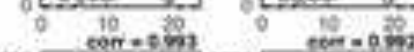
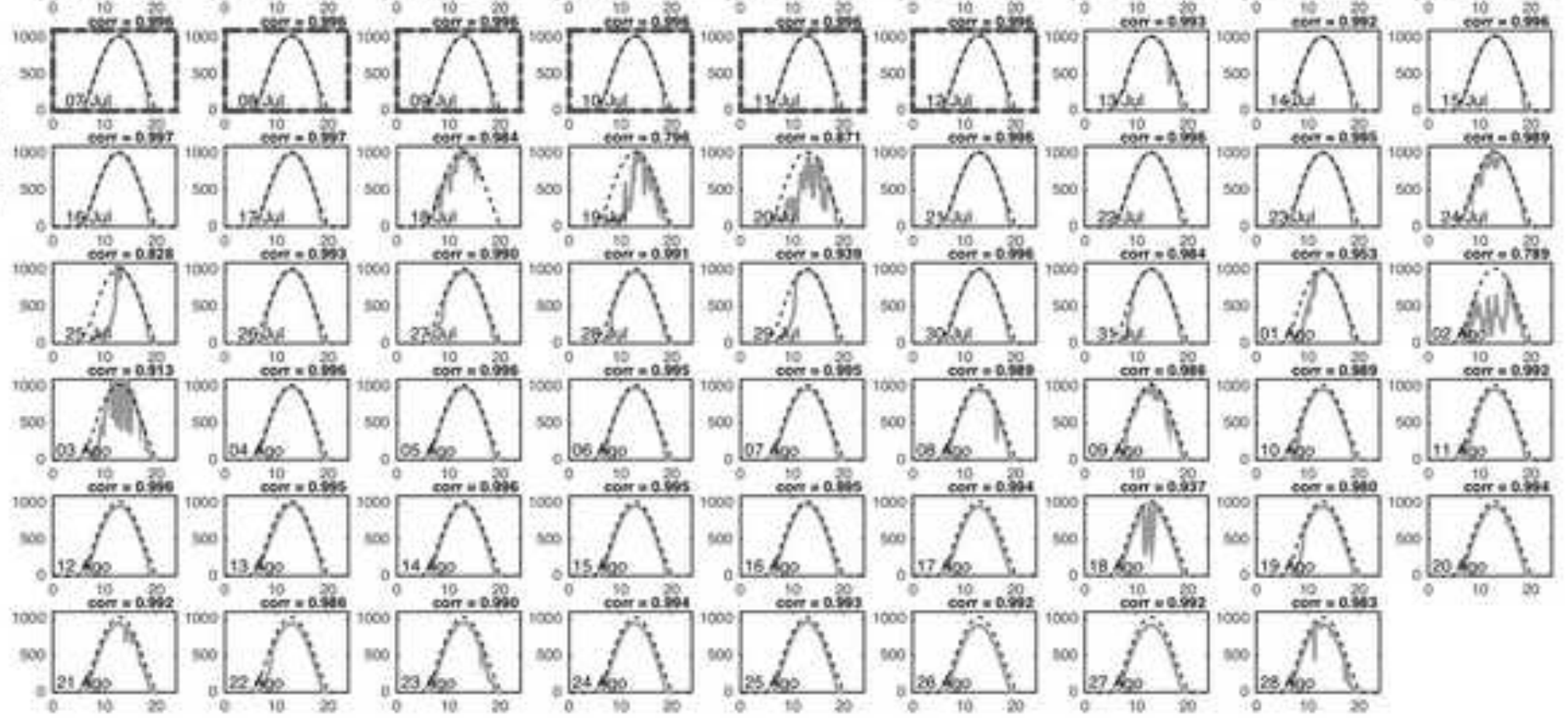

\footnotetext{
Time (hour)
} 